\title{
Implementation of street trees within the solar radiative exchange parameterization of TEB in SURFEX v8.0
}

\author{
Emilie C. Redon ${ }^{1}$, Aude Lemonsu ${ }^{1}$, Valéry Masson ${ }^{1}, B_{\text {Benjamin Morille }}^{2}$, and Marjorie Musy ${ }^{2}$ \\ ${ }^{1}$ CNRM UMR 3589, Météo-France/CNRS, Toulouse, France, 42 Avenue Gaspard Coriolis, \\ 31057 Toulouse CEDEX 1, France \\ ${ }^{2}$ Ecole nationale supérieure d'Architecture de Nantes, UMR 1563, Quai François Mitterrand, 44262 Nantes CEDEX 2, France
}

Correspondence to: Aude Lemonsu (aude.lemonsu@meteo.fr)

Received: 20 June 2016 - Published in Geosci. Model Dev. Discuss.: 1 August 2016

Revised: 4 January 2017 - Accepted: 9 January 2017 - Published: 25 January 2017

\begin{abstract}
The Town Energy Balance (TEB) model has been refined and improved in order to explicitly represent street trees and their impacts on radiative transfer: a new vegetated stratum on the vertical plane, which can shade the road, the walls, and the low vegetation has been added. This modification led to more complex radiative calculations, but has been done with a concern to preserve a certain level of simplicity and to limit the number of new input parameters for TEB to the cover fraction of trees, the mean height of trunks and trees, their specific leaf area index, and albedo. Indeed, the model is designed to be run over whole cities, for which it can simulate the local climatic variability related to urban landscape heterogeneity at the neighborhood scale. This means that computing times must be acceptable, and that input urban data must be available or easy to define. This simplified characterization of high vegetation necessarily induces some uncertainties in terms of the solar radiative exchanges, as quantified by comparison of TEB with a highspatial-resolution solar enlightenment model (SOLENE). On the basis of an idealized geometry of an urban canyon with various vegetation layouts, TEB is evaluated regarding the total shortwave radiation flux absorbed by the elements that compose the canyon. TEB simulations in summer gathered best scores for all configurations and surfaces considered, which is precisely the most relevant season to assess the cooling effect of deciduous trees under temperate climate. Mean absolute differences and biases of 6.03 and $+3.50 \mathrm{~W} \mathrm{~m}^{-2}$ for road, respectively, and of 3.38 and $+2.80 \mathrm{~W} \mathrm{~m}^{-2}$ for walls have been recorded in vegetationless canyons. In view of the important incident radiation flux, exceeding $1000 \mathrm{~W} \mathrm{~m}^{-2}$ at solar noon, the mean absolute percentage differences of $3 \%$
\end{abstract}

for both surfaces remain moderate. Concerning the vegetated canyons, we noted a high variability of statistical scores depending on the vegetation layout. The greater uncertainties are found for the solar radiation fluxes received and absorbed by the high vegetation. The mean absolute differences averaged over the vegetation configurations during summertime are $21.12 \pm 13.39 \mathrm{~W} \mathrm{~m}^{-2}$ or $20.92 \pm 10.87 \%$ of mean absolute percentage differences for the total shortwave absorption, but these scores are associated with acceptable biases: $-15.96 \pm 15.93 \mathrm{~W} \mathrm{~m}^{-2}$.

\section{Introduction}

For counteracting the adverse environmental effects that can result from continuous process of urban expansion, numerous projects of local urban planning or design support and favor the preservation and reintroduction of vegetation in the city. From an environmental point of view, the natural soils and vegetation play a important role and bring significant benefits in different sectors (Nowak and Dwyer, 2007; Mullaney et al., 2015). They act at a microclimate level through the processes of soil water evaporation and of transpiration of plants (Qiu et al., 2013). These processes cool the ambient air (Zhang et al., 2013) and mitigate the effect of the urban heat island (Feyisa et al., 2014; Önder and Akay, 2014; Alavipanah et al., 2015). High vegetation, particularly street trees in dense urban neighborhoods, create shadow areas that can locally improve the thermal comfort of pedestrians (Spangenberg et al., 2008; Shashua-Bar et al., 2011; Coutts et al., 2015; de Abreu-Harbich et al., 2015; 
Joshi and Joshi, 2015) and reduce the radiation penetration in buildings in summer (Akbari et al., 1997, 2001; Simpson, 2002; Abdel-Aziz et al., 2015; Ko et al., 2015). For some years now, green roofs are implemented more intensively in cities. The cooling effects they induce on air temperature at pedestrian level are lesser than in those of trees or groundbased vegetation but they modify the energy budget at roof level (Taleghani et al., 2016). Nonetheless, they help to reduce the temperature fluctuations of structural roofs and to better insulate buildings (Hien et al., 2007; Kokogiannakis et al., 2011). Many studies highlighted their efficiency for significant energy savings for heating and air conditioning (Jim, 2014). The implementation of pervious soils, whether at the ground or on buildings, also enables a more effective and sustainable management of rainwater by the storage of water in the soil and the decrease of surface water runoff (Armson et al., 2013; Yao et al., 2015; Zhang et al., 2015). Besides microclimatic and hydrological impacts, the urban vegetation is identified as a biodiversity reservoir for fauna and flora in cities (Alvey, 2006). It also plays its part in architectural atmospheres, and more widely in the perception of environmental quality by the population. The green spaces in an urban environment are generally perceived very positively by inhabitants because they are places of wellness, detente, and user friendliness (Bertram and Rehdanz, 2015; Bowen and Parry, 2015).

In order to investigate some of the physical processes related to the presence of vegetation in an urban environment, e.g., for microclimate, hydrology, or building energy consumption issues, the modeling is definitely a necessary tool. It is also pretty relevant and powerful to assess greening strategies by quantifying the potential impacts, and it consequently enables to answer to some important expectations of public stakeholders and urban planners.

The Town Energy Balance (TEB) urban canopy model (Masson, 2000) is applied today for many studies of climate change impacts at city scale. Among the numerous strategies of adaptation to climate change, and attenuation of the urban heat island, the benefits of urban environment greening has been investigated through more or less realistic scenarios. Kounkou-Arnaud et al. (2014) and de Munck (2013) have proposed and tested some strategies of ground-based vegetation implementation for the city of Paris (France). They have evaluated the cooling potential of this vegetation through the evapotranspiration process during summer. They investigated and quantified the impacts in terms of decrease of air temperature inside the streets, as well as improvement of thermal comfort conditions outside and inside buildings. The works of de Munck (2013) have also addressed the issues of building energy consumption and of water resource at multiyear and seasonal scales.

For such modeling exercises, TEB had been previously improved in order to explicitly represent urban vegetation within the canyon and to parameterize at small scale the radiative and energetic interactions between the built-up covers and the vegetation (Lemonsu et al., 2012). All types of vegetation are however managed as a ground-based layer: leaves can be in shade of buildings but do not create shadow effects themselves on roads or buildings. With the current developments, we attempt to remedy this lack by modifying the solar radiation budget of tree-filled canyons. The tree layer can now shade ground-based surfaces and walls. In this way, interception, transmission, or absorption of solar radiation by this additional non-opaque surface are computed. These implementations are evaluated by a comparison with simulations provided by a microscale radiation model: SOLENE, developed at the CERMA laboratory in Nantes, France.

\section{Urban high-vegetation modeling}

Until recently, very few urban climate models were able to take into account natural soils and vegetation. This fact constitutes a significant limitation in modeling the radiative and energetic exchanges in urban environments, according to the results of the intercomparison exercise of urban models performed by Grimmond et al. (2011). Most of models that already included vegetation were based on the tiling approach which consists of dealing separately with impervious covers and natural covers with distinct parameterizations and without microscale interactions between vegetation and built-up elements. However, an important effort has been conducted these last years in order to improve the representation of physical processes related to the presence of vegetation in urban climate models. Suburban and residential areas are characterized by an abundant vegetation (all types combined), while trees are predominant in cities. This feature of most cities has motivated the concern of improving urban microclimate modeling in such areas. Krayenhoff et al. (2014) present an exhaustive literature review of existing models and their characteristics.

Many different approaches are currently applied for implementing high vegetation and its implication in calculation of radiative and energetic exchanges. Among single-layer models with integrated vegetation schemes, Lee and Park (2008) were the first to deal with effects of trees in urban canyons in their vegetated urban canopy model (VUCM). The foliage layer is explicitly represented in the middle of the canyon above the ground. It is characterized by a cover fraction of the canyon, a thickness, and a vertical profile of leaf area density (LAD). The trunks are assumed to be transparent, as it is often the case in vegetation models. Radiation budget is computed for shortwave radiation (direct and diffuse components) by accounting for shadowing effects of trees on buildings and ground-based surfaces and of buildings on trees, as well as multiple reflections, and for longwave radiation with one reflection. The hypothesis of Lambertian reflectance is applied by considering each element of the canyon as a uniform surface (with uniform albedo, emissivity, and temperature). For each of them, the view factors in relation to sur- 
rounding elements are computed at the center of the surface. The attenuation of radiation by leaves is included in equations when shortwave or longwave radiation crosses the foliage. It depends on transmissivity properties of foliage - inspired by works of Yamada (1982) for forest canopies - that follow an exponential law based on the LAD profile and a modulation factor depending on vegetation type. More recently, Young et al. (2015) have developed and tested a similar parameterization for street trees (TUrban) in the singlecolumn reading urban model (SCRUM, Harman and Belcher, 2006; Porson et al., 2009). The tree canopy is explicitly described as a rectangle located in the middle of the canyon and assumed to be lower than building height. The view factors for both fully visible and partially occluded facets due to the presence of the foliage are calculated in an analytic manner, based on Hottel's crossed string construction (Hottel, 1954). The model implemented by Ryu et al. (2015) considers two explicit and symmetric trees with circular crowns. The Monte Carlo algorithm developed by Wang (2014) is executed once at the beginning of the simulation and subsequently transformed into simple relations to determine view factors for which trees are involved. Shortwave and longwave radiation exchanges but also sensible and latent heat exchanges and root water uptake processes are represented.

The building effect parameterization with trees (BEPTree) model is the first multilayer model of urban energy exchange and flow at the neighborhood scale that includes trees and both their radiative (Krayenhoff et al., 2014) and dynamic (Krayenhoff et al., 2015) effects on buildings. View factors are also computed using a Monte Carlo ray-tracing approach. The clustered distribution of tree crowns is taken into account through a unique clumping factor for all the vegetation of the canyon. Tree foliage can be present both within and above the canyon and above the roofs.

For large eddy simulations (LESs) in an urban environment, a vegetated urban canopy model (VUC) has been integrated by Tavares et al. (2015) in the advanced regional prediction system (ARPS) model. This ARPS-VUC version distinguishes the tree canopy from natural soils and groundbased vegetation. The radiative calculations are however rather simplified in relation to dynamics. The net radiation flux decreases exponentially from the top of urban canopy to the ground depending on the canopy density which includes both tree vegetation and buildings. For a microscale urban climate model such as ENVI-met (Bruse and Fleer, 1998), the fine meshing enables to resolve explicitly each element which composes the urban environment by distinguishing buildings, impervious and natural ground-based surfaces, vegetation, and air. Absorption coefficients of radiation by vegetation (based on an exponential formulation) are calculated at each vertical level, according to the vertical profile of LAD. The SOLENE-microclimat model (based on the SOLENE radiative model) is able to represent the evaporative, shading, and insulating characteristics of green walls and roofs, modeled as surfaces (Malys, 2012). The trees are (a) Without explicit high vegetation

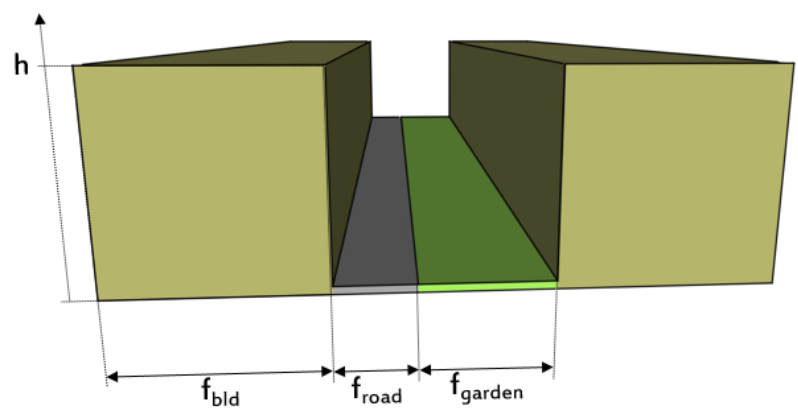

(b) With explicit high vegetation

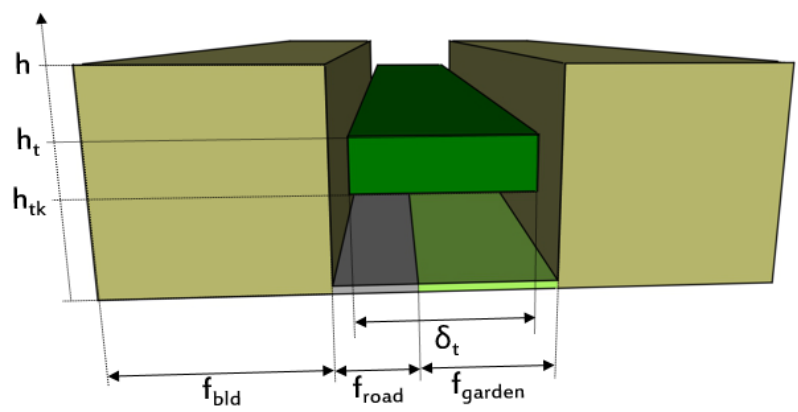

Figure 1. Comparison of the spatial arrangement of elements composing the urban canyon and of associated geometric parameters applied in the TEB model in the reference case (top) and in the case with explicit high vegetation (bottom).

modeled as porous volumes in the airflow model and as semitransparent crowns in the radiative model; the energy balance (evaporative, convective, and radiative fluxes) being coupled to these models (Robitu et al., 2006). This balance leads to the assessment of leaves and air temperatures.

\section{General concept of TEB and urban trees representation}

\subsection{Description of urban areas in TEB}

At each mesoscale model grid point, TEB describes the average characteristics of the local environment by a single urban canyon composed of a ground-based surface bordered by two flat-roof buildings of same height. The urban environment is thus described in TEB based on four distinct elements that compose the urban canyons: "roof", "wall", and for the ground-based surfaces, a combination of impervious and natural covers referred to as "road" and "garden", respectively (Fig. 1).

A set of geometric parameters are defined to describe the canyon (Table 1): cover fractions of buildings and gardens (the remaining fraction is assumed to be the roadways), mean building height, and wall area density. Impervious covers are also characterized by radiative and thermal properties de- 
Table 1. Main descriptive parameters of the urban canyon, including vegetation, in the TEB model. The parameters followed by an asterisk are the input data prescribed by user, the other ones are computed in the model using the input parameters.

\begin{tabular}{lll}
\hline Parameters & Symbol & Unit \\
\hline Cover fraction of buildings* & $f_{\mathrm{bld}}$ & - \\
Cover fraction of ground-based natural covers (garden)* & $f_{\mathrm{garden}}$ & - \\
Proportion of bare soil in gardens* & $\delta_{\mathrm{nv}}$ & - \\
Proportion of low vegetation in gardens & $\delta_{\mathrm{lv}}=1-\delta_{\mathrm{nv}}$ & - \\
Cover fraction of tree canopy* & $\delta_{\mathrm{t}}$ & - \\
Mean building height* & $h$ & $\mathrm{~m}$ \\
Wall plan area ratio* & $r_{\mathrm{w}}$ & - \\
Canyon aspect ratio & $h / w=0.5 r_{w} /\left(1-f_{\mathrm{bld}}\right)$ & - \\
Height of tree canopy* & $h_{\mathrm{t}}$ & $\mathrm{m}$ \\
Height of trunk* & $h_{\mathrm{tk}}$ & $\mathrm{m}$ \\
Mid-height of tree's crown & $h_{\mathrm{cw}}=\left(h_{\mathrm{t}}+h_{\mathrm{tk}}\right) / 2$ & $\mathrm{~m}$ \\
Sky view factor of wall, road, garden, tree & $\Psi_{\mathrm{ws}}, \Psi_{\mathrm{rs}}, \Psi_{\mathrm{gs}}, \Psi_{\mathrm{ts}}$ & - \\
View factor of road, tree from wall & $\Psi_{\mathrm{wr}}, \Psi_{\mathrm{wt}}$ & - \\
View factor of wall, tree from road & $\Psi_{\mathrm{rw}}, \Psi_{\mathrm{rt}}$ & - \\
View factor of wall, road from tree & $\Psi_{\mathrm{tw}}, \Psi_{\mathrm{tr}}$ & - \\
Leaf area index of low vegetation in gardens* & $\mathrm{LAI}_{\mathrm{g}}$ & $\mathrm{m}^{2} \mathrm{~m}^{-2}$ \\
Leaf area index of tree canopy* & $\mathrm{LAI}_{\mathrm{t}}$ & $\mathrm{m}^{2} \mathrm{~m}^{-2}$ \\
Leaf area density of tree canopy & $\mathrm{LAD}_{\mathrm{t}}$ & $\mathrm{m}^{2} \mathrm{~m}^{-3}$ \\
Albedo of wall, road, garden, tree* & $\alpha_{\mathrm{w}}, \alpha_{\mathrm{r}}, \alpha_{\mathrm{g}}, \alpha_{\mathrm{t}}$ & - \\
Emissivity of wall, road, garden, tree* & $\epsilon_{\mathrm{w}}, \epsilon_{\mathrm{r}}, \epsilon_{\mathrm{g}}, \epsilon_{\mathrm{t}}$ & - \\
\hline
\end{tabular}

pending on construction materials: albedo and emissivity are prescribed for outdoor surface coating of roofs, walls, and roads; thermal conductivity and heat capacity are defined for the ensemble of materials composing buildings and roadways. For each urban facet (roof, walls, and road) separately, the model computes a radiation budget and a surface energy balance. It also resolves an equation of temperature evolution with a single surface temperature associated with each facet.

For natural soils and vegetation, the radiative and energetic exchanges with atmosphere, as well as the hydrological and thermal processes in the ground, are parameterized with the interaction soil-biosphere-atmosphere model (ISBA) model (Noilhan and Planton, 1989). The vegetation stratum is described in the ISBA model as an aggregation of bare soil, low stratum (grass), and high stratum (trees) of vegetation. This vegetation stratum is characterized by composite descriptive and physiologic properties that are calculated starting from properties of these different types of natural covers. They include albedo and emissivity (depending of proportion of bare soil and vegetation), leaf area index, stomatal resistance, and roughness length. Note that some of those properties can evolve seasonally, but also in the event of snowfall which modifies radiative properties. The vegetation stratum is connected with a soil column, with which hydrological and thermal properties are associated depending on soil texture and water content evolution (Boone et al., 1999).

This reference version of TEB is based on two important simplifications. First, there is no explicit spatial arrangement of the garden within the canyon. They are only represented as land cover fractions. In addition, the vegetation stratum, even if it can be composed of trees (through the definition of specific physiological properties), is always placed on the ground without vertical extent. This means that shadow effects on the ground and buildings related to the presence of high vegetation are not taken into account, and that there is no vertical distribution of turbulent energy exchanges between vegetation and atmosphere.

\subsection{General principles of solar radiation exchange parameterization in TEB}

The present study describes the improvements of the radiation budget calculations in TEB by the implementation of explicit high vegetation. Consequently, this section is focused on the description of the radiative exchanges in the initial version of TEB. The parameterization of turbulent heat fluxes and of heat conduction processes, as well as the calculations of microclimate parameters within the canyon, are not presented here but they are detailed by Masson (2000), Lemonsu et al. (2004), Hamdi and Masson (2008), Masson and Seity (2009), and Lemonsu et al. (2012).

The TEB urban canyons are assumed to be of infinite length so that there is no street intersection. The radiative calculations are consequently done on a two-dimensional plane which crosses the canyon according to an axis perpendicular to the street direction. Two main options are available for radiative calculations: (1) a street orientation can be prescribed, so that the two walls of the canyon (referred to as "wall A" and "wall B") are managed separately; or (2) the 
hypothesis of isotropic orientation of streets is applied, and in this case, walls are managed together (implying that they will have identical temperature evolutions).

The shortwave and longwave radiation budgets are resolved in TEB for each element composing the urban canyon (roofs, walls, road, ground-based vegetation, and now tree canopy) with the aim of determining the energy absorbed by each element that is used afterward to compute the surface energy budget.

More specifically for the shortwave radiation budget, three contributions are considered for a given element:

1. The direct solar radiation received before any reflections depends on zenith angle since the incident direct radiation is unidirectional, street orientation, and canyon aspect ratio.

2. The diffuse solar radiation received before any reflections depends on the sky view factor of the considered element since the diffuse radiation is assumed to be isotropic.

3. Finally, the total shortwave radiation received after multiple reflections within the canyon is computed. After a first reflection on one of the elements of the canyon, initial contributions of direct and diffuse radiation are isotropic and are treated the same way. The part of radiation received by a given element then depends on the view factors of all the other elements and on their albedo to determine the reflected radiation part.

Although this paper focuses on resolution and evaluation of the shortwave radiation budget, it is worth to note that the validation of our shortwave radiation scheme contributes to verifying our future longwave radiation scheme. Indeed, the same view factors used for the multiple reflections will be applied to the longwave radiation interactions within the canyon. The longwave exchanges are computed following a linear approximation of the Stefan-Boltzmann law. For numerical stability purposes, an implicit formulation is applied for longwave radiation budgets; it includes the surface temperatures at the previous numerical time step and at the current time step.

\subsection{Inclusion of a high-vegetation stratum for solar radiation calculation}

To take into account the tree canopy in TEB, it is required to add a new vegetated stratum on the vertical plane, which can shade the road, the walls, and the low vegetation. This modification led to more complex radiative calculations, but is done with a concern to preserve a certain level of simplicity and to limit the number of new input parameters for TEB. This is motivated by the type of applications which are conducted with the TEB model, and more generally with the SURFEX land surface modeling platform (Masson et al., 2013) which TEB is part of. The system is frequently applied over domains of several hundred square kilometers with horizontal resolutions between a few hundred meters and a few kilometers and can be run for long time periods up to several years in the cases of climatic studies (e.g., Lemonsu et al., 2013; de Munck, 2013, in French). This means that computing times must be acceptable, and that urban input data must be available or easy to define.

The arrangement of tree canopy is described here using three parameters only (Fig. 1 and Table 1): its cover fraction $\left(\delta_{t}\right)$, i.e., the proportion of canyon which is covered by the foliage stratum on the horizontal plane, as well as the mean height of trees $\left(h_{\mathrm{t}}\right)$, and the mean height of trunks $\left(h_{\mathrm{tk}}\right)$. In the current version of TEB (official SURFEX v8.0), urban trees are assumed to be less tall than surrounding buildings and systematically confined inside the canyon so that they cannot provide shade for roofs. This hypothesis is in accordance with common urban planning specifications for street tree management in Europe (in French, Municipality of Toulouse, 2008; City of Westminster, 2009; Barcelona City Council, 2011). These documents ensure a satisfactory juxtaposition of trees with urban structures for dwellers. Minimum distances between trunks or crowns and walls or balconies are strictly imposed to avoid problems such as excessive obstruction of crowns facing windows, disruption of underground services by roots or subsidence of buildings. These widespread practices are also applied in private gardens or suburban areas and tend to avoid shadow on roofs even if street trees can be taller than buildings. Design with trees shading roofs is statistically sparse and their impact on surface balance is limited. At this stage, the application of TEB to low-density neighborhoods is restricted if trees can significantly shade buildings. They are probably located in high latitudes where incoming fluxes are lower than in midlatitudes or low latitudes, and this potential bias would only occur in the early morning or late evening, when the zenith angle is large but the solar radiation flux far less energetic than around noon.

For now, the shape of the foliage and the vertical distribution of leaves are not defined. The crowns of trees are considered as rectangular parallelepipeds (namely computed as a rectangular cross-section in a two-dimensional plane perpendicular to the street axis) with homogeneous foliage which is described by a leaf area index $\left(\mathrm{LAI}_{\mathrm{t}}\right)$ and an albedo $\left(\alpha_{\mathrm{t}}\right)$. It is however possible to vary the LAI during the year, in order to simulate the seasonal cycle of deciduous trees. The high-vegetation cover fraction is a combination of the sum of widths of crowns in the plane perpendicular to the street axis but also takes into account the presence or lack of gaps between crowns lengthwise along the canyon. Note that trunks are not taken into account in radiative calculations. The tree vegetation stratum is considered as a partially transparent element for shortwave radiation. A part of the incident radiation received by trees is transmitted through the foliage. The part of radiation which is not transmitted is consequently re- 
flected or absorbed, depending on albedo. These processes and the associated calculations are detailed hereafter.

\section{Solar radiation absorption of vegetated street canyon surfaces}

In this part, equations related to the implementation of a tree layer into the TEB model are presented. In order to calculate these terms in TEB, Sect. 4.1 and 4.2 describe how direct and diffuse solar radiation fluxes reach canyon surfaces. Then, absorption is obtained by separately resolving the first absorption of total shortwave radiation on each surface and the sum of absorbed shortwave radiation after infinite reflections within the canyon.

\subsection{Direct solar radiation received by each element}

The foliage of trees plays a role of obstruction and attenuation of incident direct solar radiation $\left(S^{\Downarrow}\right)$ for the other elements of the urban canyon. Consequently, to determine the direct solar radiation received by each element of the canyon, we need to first solve the equations related to high vegetation.

The direct solar radiation potentially reaching the top of trees by geometrically taking into account the shading of buildings depends on building height $(h)$, canyon aspect ratio $(h / w)$, street orientation $\left(\theta_{\text {can }}\right)$, zenith and azimuth angles $(\lambda$, $\left.\theta_{\text {sun }}\right)$, as well as tree height $\left(h_{\mathrm{t}}\right)$ :

$S_{\mathrm{t}}^{\Downarrow}=$

$S^{\Downarrow} \max \left[0 ; 1-\frac{h}{w}\left(\frac{h-h_{\mathrm{t}}}{h}\right) \tan (\lambda) \sin \left|\theta_{\text {sun }}-\theta_{\text {can }}\right|\right]$.

As previously explained, this radiation flux is partially transmitted through the foliage $\left(S_{\mathrm{t}}^{\gg}\right)$, whereas the remaining solar radiation is reflected $\left(S_{\mathrm{t}}^{\Uparrow}\right)$ or absorbed $\left(S_{\mathrm{t}}^{*}\right)$ :

$S_{\mathrm{t}}^{\Downarrow}=S_{\mathrm{t}}^{\gg}+S_{\mathrm{t}}^{\Uparrow}+S_{\mathrm{t}}^{*}$.

The proportion of direct solar radiation transmitted through the foliage is estimated by the Beer-Lambert law (Campbell and Norman, 1989) where the leaf area index (LAI $\mathrm{I}_{\mathrm{t}}$, expressed in $\mathrm{m}^{2}$ of leaves per $\mathrm{m}^{2}$ of ground) of tree canopy and an extinction coefficient $(k)$ are involved. The extinction coefficient is fixed to 0.5 , a default value corresponding to a homogeneous distribution of leaves in terms of density and orientation (in other words, a spherical leaf angle distribution):

$S_{\mathrm{t}}^{\gg}=S_{\mathrm{t}}^{\Downarrow} \exp ^{\left(-k \mathrm{LAI}_{\mathrm{t}}\right)}$.

The reflected radiation part simply depends on the part of incident solar radiation untransmitted through the foliage and on the albedo of trees $\left(\alpha_{t}\right)$ :

$S_{\mathrm{t}}^{\Uparrow}=\alpha_{\mathrm{t}} S_{\mathrm{t}}^{\Downarrow}\left(1-\exp ^{\left(-k \mathrm{LAI}_{\mathrm{t}}\right)}\right)$.
Finally, the incident direct solar radiation part absorbed by trees is neither transmitted nor reflected and calculated as the residual term from Eq. (2):

$S_{\mathrm{t}}^{*}=\left(1-\alpha_{\mathrm{t}}\right) S_{\mathrm{t}}^{\Downarrow}\left(1-\exp ^{\left(-k \mathrm{LAI}_{\mathrm{t}}\right)}\right)$.

The direct solar radiation received by the ground (indiscriminately road or garden fraction) is deduced by correcting the incident solar radiation above the canyon from the interception of radiation by high-vegetation canopy (i.e., reflected and absorbed radiation weighted by high-vegetation cover fraction, referred to as $\delta_{\mathrm{t}}$ ), and then from the shading effects of buildings (according to Lemonsu et al., 2012). The same equations are obtained for road $\left(S_{\mathrm{r}}^{\Downarrow}\right)$ and $\operatorname{garden}\left(S_{\mathrm{g}}^{\Downarrow}\right)$ :

$$
\begin{aligned}
S_{\mathrm{r}}^{\Downarrow}= & \left(S^{\Downarrow}-\delta_{\mathrm{t}}\left(S_{\mathrm{t}}^{\Uparrow}+S_{\mathrm{t}}^{*}\right)\right) \\
& \max \left[0 ; 1-\frac{h}{w} \tan (\lambda) \sin \left|\theta_{\text {sun }}-\theta_{\text {can }}\right|\right] .
\end{aligned}
$$

In this way, tree foliage is assumed to be uniformly distributed across the canyon at the height of the trees $\left(h_{\mathrm{t}}\right)$, consistently with Eq. (1).

The direct solar radiation which is not received by high vegetation, road or garden is assigned to the sunlit wall, whereas the opposite wall is in the shadow. By convention in TEB in the case of an oriented canyon, we define wall A as the most sunlit wall and wall B as the shaded one.

$S_{\mathrm{w}_{\mathrm{A}}}^{\Downarrow}=\left(S^{\Downarrow}-S_{\mathrm{r}}^{\Downarrow}-\delta_{\mathrm{t}}\left(S_{\mathrm{t}}^{\Uparrow}+S_{\mathrm{t}}^{*}\right)\right) \frac{w}{h}$

$S_{\mathrm{w}_{\mathrm{B}}}^{\Downarrow}=0$

Note that shading effects of high vegetation on roofs are not represented, since urban trees are less tall than buildings by definition in the current version of TEB (SURFEX v8.0).

\subsection{Diffuse solar radiation received by each element}

The incoming diffuse solar radiation $\left(S^{\downarrow}\right)$ is assumed to emit isotropically. Each urban surface of the canyon (wall, road, and garden) receives a part of diffuse solar radiation according to the sky view factor of the surface $\Psi_{*}$ (see Appendix A) and the mean radiative transmissivity between the sky and the given surface $\tau_{* \mathrm{~s}}$ (see Appendix B). Note that the sky view factor of "wall" is defined at mid-height of buildings; for ground-based surfaces "road" and "garden", a single sky view factor $\Psi_{\mathrm{rs}}=\Psi_{\mathrm{gs}}$ is defined at the center of the street (Masson, 2000; Lee and Park, 2008). The following equations are obtained for "road" (same expression for "garden") and for "wall":

$S_{\mathrm{r}}^{\downarrow}=S^{\downarrow} \Psi_{\mathrm{rs}} \tau_{\mathrm{rs}}$

$S_{\mathrm{w}}^{\downarrow}=S^{\downarrow} \Psi_{\mathrm{ws}} \tau_{\mathrm{ws}}$.

We admit that the residual flux of diffuse solar radiation which is not intercepted in the canyon by previous surfaces 
reaches the tree canopy:

$S_{\mathrm{t}}^{\downarrow}=\frac{S^{\downarrow}-\left(\delta_{\mathrm{r}} S_{\mathrm{r}}^{\downarrow}+\delta_{\mathrm{g}} S_{\mathrm{g}}^{\downarrow}+\frac{2 h}{w} S_{\mathrm{w}}^{\downarrow}\right)}{\delta_{\mathrm{t}}}$.

This method presents two major advantages: (1) the diffuse solar radiation budget is always closed, and (2) the computed diffuse solar radiation flux for the high vegetation is already corrected from the transmitted part, reaching the other surfaces.

The fluxes of each surface are expressed here according to the total ground-based surface of the canyon, with $\delta_{\mathrm{r}}$ and $\delta_{\mathrm{g}}$ the cover fractions of road and garden in the canyon $\left(\delta_{\mathrm{r}}+\delta_{\mathrm{g}}=\right.$ $1)$, respectively.

\subsection{First absorption of total shortwave radiation by each element}

The first absorption of total shortwave radiation $S^{*}(0)$, before any reflections, is only a function of the total shortwave radiation received by the considered element and of its albedo $\left(\alpha_{*}\right)$. The same expression is obtained for walls and groundbased surfaces (* which stands for "r", "g", "wA", or "w "

$S_{*}^{*}(0)=\left(1-\alpha_{*}\right)\left(S_{*}^{\Downarrow}+S_{*}^{\downarrow}\right)$

For the tree canopy, the part of absorbed direct solar radiation is corrected by the transmitted flux:

$S_{\mathrm{t}}^{*}(0)=\left(1-\alpha_{\mathrm{t}}\right)\left[\left(S_{\mathrm{t}}^{\Downarrow}-S_{\mathrm{t}}^{\gg}\right)+S_{\mathrm{t}}^{\downarrow}\right]$.

$S_{\mathrm{t}}^{\Downarrow}$ includes the transmitted flux $S_{\mathrm{t}}^{\gg}$ (see Eq. 2) contrary to $S_{\mathrm{t}}^{\downarrow}$ which is calculated as a residual flux (Eq. 11), corrected from the transmitted flux.

\subsection{Sum of total shortwave radiation absorbed by each element}

Our goal is to compute the total shortwave radiation absorption for each element $S^{*}(\infty)$ by taking into account an infinite number of reflections between all elements composing the urban canyon. At each reflection, the isotropic radiation intercepted by a given element, (1), after reflections on one of the other elements, (2), is conditioned by the view factor of (2) from (1), referred to as $\Psi_{12}$ (see Appendix A), the mean radiative transmissivity $\tau_{12}$ (see Appendix B), and the absorption is then determined according to reflective properties of (1). Using a single view factor in TEB radiation calculations is obviously a limitation for accurately representing the various contributions of canyon's surfaces to high vegetation. Additionally, we have a poor knowledge of the forward scattering or trapping effects occurring within the crowns. Because of the description of the canopy as a surface, TEB neglects these processes, but the attenuation and transmission applied at the top of the canopy (see Eqs. 3, 4, and 5 arising from Eq. 1) could be adjusted in order to implicitly include these phenomena. To ensure a closing system, we define the total absorbed shortwave radiation by high vegetation as the remaining shortwave radiation, after accounting for absorption and reflection from the total incident solar radiation by all other elements of the canyon. This requires calculating the part of shortwave radiation which leaves the canyon towards the sky. The terms $R_{\infty}, G_{\infty}, A_{\infty}, B_{\infty}$, and $T_{\infty}$ make reference to the sum of total shortwave radiation reflected by each surface, respectively, after an infinite number of reflections (see detailed resolution in Appendix C). Here is the expression of the total absorbed solar flux per surface:

$$
\begin{aligned}
S_{\mathrm{s}}^{*}(\infty)= & \Psi_{\mathrm{sr}} \tau_{\mathrm{sr}}\left(\delta_{\mathrm{r}} R_{\infty}+\delta_{\mathrm{g}} G_{\infty}\right) \\
& +\Psi_{\mathrm{sw}} \tau_{\mathrm{sw}} \frac{A_{\infty}+B_{\infty}}{2}+\Psi_{\mathrm{st}} \delta_{\mathrm{t}} T_{\infty} \\
S_{\mathrm{r}}^{*}(\infty)= & S_{\mathrm{r}}^{*}(0)+\left(1-\alpha_{\mathrm{r}}\right) \\
& {\left[\Psi_{\mathrm{rw}} \tau_{\mathrm{rw}} \frac{A_{\infty}+B_{\infty}}{2}+c_{\mathrm{rt}} \Psi_{\mathrm{rt}} \delta_{\mathrm{t}} T_{\infty}\right] } \\
S_{\mathrm{g}}^{*}(\infty)= & S_{\mathrm{g}}^{*}(0)+\left(1-\alpha_{\mathrm{g}}\right) \\
& {\left[\Psi_{\mathrm{rw}} \tau_{\mathrm{rw}} \frac{A_{\infty}+B_{\infty}}{2}+c_{\mathrm{rt}} \Psi_{\mathrm{rt}} \delta_{\mathrm{t}} T_{\infty}\right] } \\
S_{\mathrm{w}_{\mathrm{A}}}^{*}(\infty)= & S_{\mathrm{w}_{\mathrm{A}}}^{*}(0)+\left(1-\alpha_{\mathrm{w}}\right)\left[\Psi _ { \mathrm { wr } } \tau _ { \mathrm { wr } } \left(\delta_{\mathrm{r}} R_{\infty}\right.\right. \\
& \left.\left.+\delta_{\mathrm{g}} G_{\infty}\right)+\Psi_{\mathrm{ww}} \tau_{\mathrm{ww}} B_{\infty}+c_{\mathrm{wt}} \Psi_{\mathrm{wt}} \delta_{\mathrm{t}} T_{\infty}\right] \\
S_{\mathrm{w}_{\mathrm{B}}}^{*}(\infty)= & S_{\mathrm{w}_{\mathrm{B}}}^{*}(0)+\left(1-\alpha_{\mathrm{w}}\right)\left[\Psi _ { \mathrm { wr } } \tau _ { \mathrm { wr } } \left(\delta_{\mathrm{r}} R_{\infty}\right.\right. \\
& \left.\left.+\delta_{\mathrm{g}} G_{\infty}\right)+\Psi_{\mathrm{ww}} \tau_{\mathrm{ww}} A_{\infty}+c_{\mathrm{wt}} \Psi_{\mathrm{wt}} \delta_{\mathrm{t}} T_{\infty}\right] \\
& \frac{1}{\delta_{\mathrm{t}}}\left[\left(S^{\Downarrow}+S^{\downarrow}\right)-\left(S_{\mathrm{s}}^{*}(\infty)+\delta_{\mathrm{r}} S_{\mathrm{r}}^{*}(\infty)\right.\right. \\
& \left.\left.+\delta_{\mathrm{g}} S_{\mathrm{g}}^{*}(\infty)+\frac{2 h}{w} \frac{S_{\mathrm{w}_{\mathrm{A}}}^{*}(\infty)+S_{\mathrm{w}_{\mathrm{B}}}^{*}(\infty)}{2}\right)\right] \\
S_{\mathrm{t}}^{*}(\infty) &
\end{aligned}
$$

The view factors related to the high-vegetation stratum are expressed in Appendix A. Specific coefficients are applied, in the shortwave scheme only, to constrain the reflections from the high vegetation toward the sky and the top part of walls. In nature, the solar radiation is mainly redirected upwards by the receiving face of sunlit leaves in the top of crown during the first reflection. We suggest here to neglect the small amount of shortwave radiation which the tree stratum is supposed to reflect to the low part of the canyon during multiple reflections in favor of realistically representing the upward isotropic first reflection of solar radiation, which is by far the most energetic reflection. Solar reflection calculations are fully explained in Appendix C. As previously mentioned, view factors used for the multiple reflections in the shortwave radiation scheme will be applied to the longwave radiation interactions within the canyon in future works. 


\section{Comparative exercise with the SOLENE model}

An objective and exhaustive assessment of the new solar radiation calculations in TEB related to the inclusion of tree layer effects is not an easy exercise, essentially due to the lack of experimental data. Indeed, very few measurements for documenting radiative effects of trees in an urban environment are available (Park et al., 2012). The objective here is to quantify the performances of TEB in simulating the different contributions of the solar radiation budget for the ensemble of urban facets and vegetation. For this purpose, we compare TEB with the SOLENE software, which is a highspatial-resolution solar and lighting architectural model and which is used in this work as a reference. Various configurations of urban canyons with street trees (that differ in terms of vegetation density and spatial distribution) are studied so that the capacities and limits of the TEB geometric approach can be highlighted and evaluated.

\subsection{General presentation of the SOLENE model}

The SOLENE model (Miguet and Groleau, 2002; Robitu et al., 2006; Groleau and Mestayer, 2013) incorporates a radiative transfer scheme based on the radiosity method which is applied to meshed scenes with triangular facets, particularly adapted to complex geometries (Bouyer et al., 2011; Malys et al., 2014). This model provides a good tool to study urban radiation distinguishing solar radiations (separate direct and diffuse components, $0.3-2.5 \mu \mathrm{m}$ ) and infrared thermal radiations $(2.5-18 \mu \mathrm{m})$.

In this research work, we consider the shortwave radiation scheme only. The incoming direct solar radiation is calculated by considering the sun as a point source, related to solar height (following the formula in De Brichambaut, 1963) and angle of incidence of rays at the surface (Miguet, 2000). The incoming diffuse part of solar radiation is represented as a non-uniform distribution coming from a sky vault defined by a hemisphere of infinite radius, which is meshed using a geodesic triangulation. The luminance values that are mapped on the hemisphere are derived from the Perez model (Perez et al., 1993). This model, based on five sky clearness and brightness parameters, provides statistical distribution depending on weather type represented. Multiple reflections are computed assuming that the surfaces are Lambertian and opaque for urban surfaces while the vegetation surfaces are semitransparent (Robitu et al., 2006). Solar simulations are performed in successive stages. The first one, based on geometric procedures, determines the visibility considering solar masks between two mesh elements or a mesh element and a sky patch of the sky vault model (including sun). View factors (including sky view factors) are produced for each mesh. The second stage calculates the solar radiation fluxes received by each mesh element for the time step. Then, the multiple reflections are computed by the radiosity method.
This last stage provides the net solar flux received by each mesh as well as absorbed and reflected parts.

The trees have been implemented from the evolution of SOLENE into the microclimate model named SOLENEmicroclimat (Robitu et al., 2006). In this new model, the trees are geometrically modeled by their external envelope and are considered as semitransparent. Therefore, a percentage of the solar radiation is transmitted by the tree canopy according to a transmission coefficient (fixed to 0.5) and directionally reaches the other elements of the urban scene. The intercepted part of the solar radiation flux is either reflected or absorbed, depending on the tree albedo. Radiative properties of the high vegetation are homogeneously applied to all the meshes which belong to the surface of vegetation blocks. A separate balance is computed for each mesh using specific view factors. Currently, no explicit foliage elements or intracanopy processes (as forward scattering) are represented in the radiative model of trees in SOLENE-microclimat.

\subsection{Configuration of numerical experiments}

\subsubsection{Canyon modeling in SOLENE}

The urban canyon geometry chosen for building SOLENE's mockups is as simple as possible to reflect the hypotheses of TEB: an infinite street ( $150 \mathrm{~m}$ in length in the mockups) bordered by two identical buildings with flat roofs. As shown in Fig. 2, it is defined here in three different urban canyon forms corresponding to aspect ratios (referred to as $h / w$ ) of $0.5,1$, and 2. For the first two aspect ratios, the building height is $8 \mathrm{~m}$ and the width of the street is $16 \mathrm{~m}$ for $h / w=0.5$ and $8 \mathrm{~m}$ for $h / w=1$. For $h / w=2$, building height is $16 \mathrm{~m}$ and width of the street is $8 \mathrm{~m}$.

For each of these urban canyons, 13 different vegetation layouts are prescribed (Fig. 3), as well as a control case without vegetation. The vegetation blocks are rectangular parallelepipeds representing the three-dimensional tree crowns, without the trunk. These solid volumes are continuous lengthwise along the canyon. Depending on the configurations, the trees can be organized in single or double rows. According to a cut plan through the canyon, the tree crowns can fill 30,60 , or $90 \%$ of canyon width. For the three aspect ratios, height of trees is prescribed to 5 or $7.5 \mathrm{~m}$ with trunks of 2.5 or $5 \mathrm{~m}$, so that the thickness of tree canopy varies between 2.5 and $5 \mathrm{~m}$. Additional configurations (referred to as $h / w=2$ rescaled vegetation) are tested, for which height of trees is prescribed to 10 or $15 \mathrm{~m}$ with trunks of 5 or $10 \mathrm{~m}$, depending on the thickness and the location of the crown (cf. Fig. 2). In other words, vegetation layer is doubly thicker and higher than $h / w=0.5$ and $h / w=1$ cases for each vegetation configuration in order to rescale it for higher buildings and verify the effect of adapted vegetation layouts regarding the typology of the street. For all experiments, the leaf area index of trees is prescribed to 1 , and the albedo is prescribed 
(a) $\mathrm{h} / \mathrm{w}=0.5$

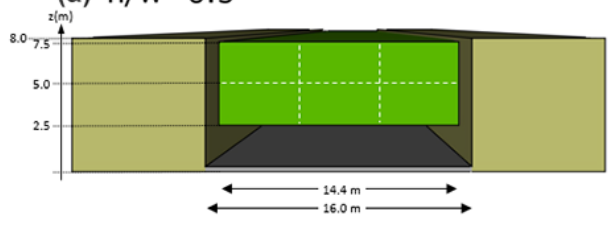

(c) $h / w=2$

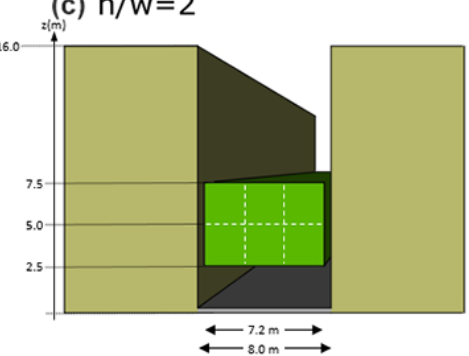

(b) $h / w=1$

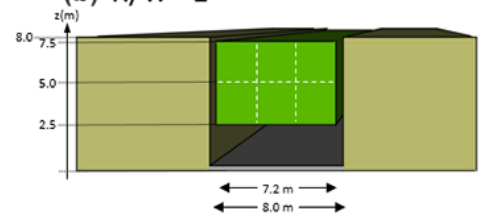

(d) $\mathrm{h} / \mathrm{w}=2$ rescaled vegetation

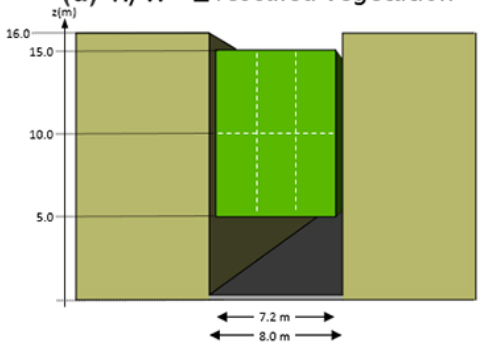

Figure 2. Description of simple geometries of an urban canyon selected for the comparison between TEB and SOLENE simulations. For each of them, the potential location of tree canopy is illustrated by dotted rectangles.
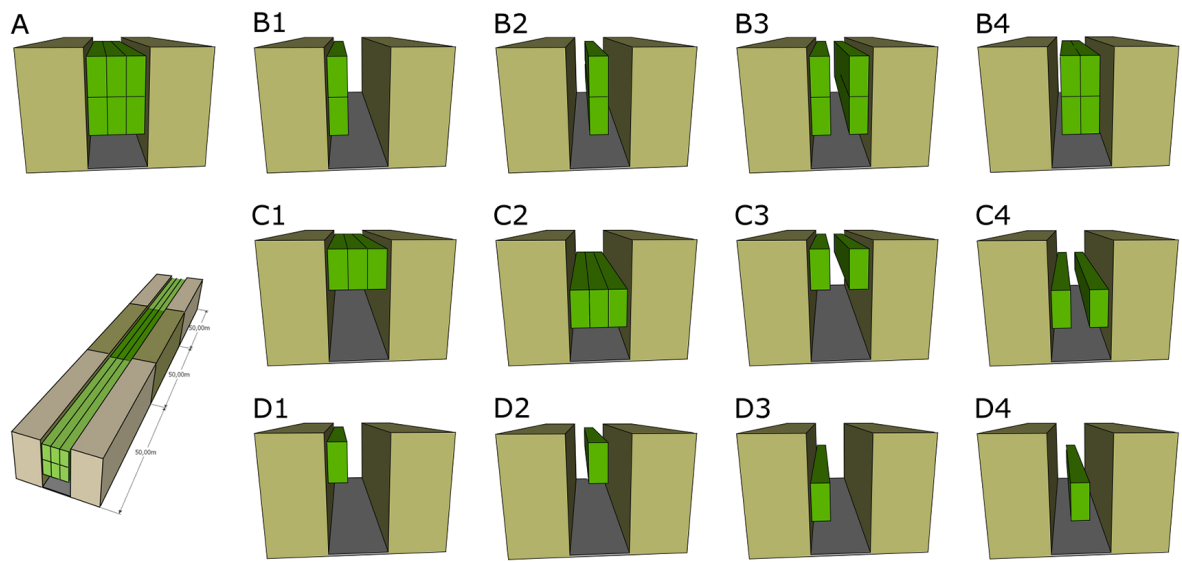

Figure 3. Description of the SOLENE mockup and presentation of the ensemble of vegetation layouts selected for the comparison between TEB and SOLENE simulations. The cases are presented here for the example of the urban canyon with $h / w=2$ rescaled vegetation (see Sect. 5.2.1 and Fig. 2 for further explanations).

to 0.25 for road, 0.30 for walls, and 0.25 for trees. All configurations are described in Figs. 1, 2, 3, and Table 2.

To treat the ensemble of configurations, 55 digital mockups (52 canyons with vegetation and 3 canyons without vegetation) have been built with the computer-aided design (CAD) software Salome V7_4_0. All mockups have been meshed by the GMSH software which is a finite element mesh generator. We have applied a non-uniform meshing here, with a characteristic length of only $1 \mathrm{~m}$ in order to refine the spatial discretization of vegetation blocks, whose smallest ones for some of the vegetation layouts do not exceed $2.4 \mathrm{~m}$ width and $2.5 \mathrm{~m}$ height.

Each canyon is projected following the four street orientations $0,45,90$, and $135^{\circ}$ (degrees from geographical north, in the counter trigonometric direction). A specific location (defined by latitude and longitude) must be prescribed for astronomic calculations. The city of Nantes (France) is chosen in an arbitrary manner $\left(46^{\circ} \mathrm{N}, 1^{\circ} \mathrm{E}\right)$. The solar radiation exchanges are then calculated for a single daily cycle, and under sunlight conditions covering the four seasons by selecting dates close to equinoxes and solstices of the year 2010 , i.e., 20 March, 21 June, 23 September, and 23 December of 2010. Note also that the Perez model (see Sect. 5.1) has been parameterized in order to generate perfectly clear cloudless skies.

\subsubsection{Canyon modeling in TEB}

In the same way, TEB is run for equivalent configurations to SOLENE configurations, respecting hypotheses, approaches, and spatial resolution differences between the two models. For TEB simulations, the geometrical parameters describing 
Table 2. List of input parameters for the ensemble of simulations performed with TEB.

\begin{tabular}{|c|c|c|c|c|c|c|c|c|c|c|c|c|c|}
\hline Parameters & A & B1 & B2 & B3 & B4 & $\mathrm{C} 1$ & $\mathrm{C} 2$ & $\mathrm{C} 3$ & $\mathrm{C} 4$ & D1 & D2 & D3 & D4 \\
\hline$f_{\text {bld }}$ & 0.5 & 0.5 & 0.5 & 0.5 & 0.5 & 0.5 & 0.5 & 0.5 & 0.5 & 0.5 & 0.5 & 0.5 & 0.5 \\
\hline$f_{\text {garden }}$ & 0 & 0 & 0 & 0 & 0 & 0 & 0 & 0 & 0 & 0 & 0 & 0 & 0 \\
\hline$\delta_{\mathrm{t}}$ & 0.9 & 0.3 & 0.3 & 0.6 & 0.6 & 0.9 & 0.9 & 0.6 & 0.6 & 0.3 & 0.3 & 0.3 & 0.3 \\
\hline$h$ & \multicolumn{13}{|c|}{8 (for $h / w=0.5, h / w=1, h / w=2$ - classical case); 16 (for $h / w=2-$ rescaled vegetation) } \\
\hline$r_{\mathrm{W}}$ & \multicolumn{13}{|c|}{0.5 (for $h / w=0.5) ; 1.0$ (for $h / w=1) ; 2.0$ (for $h / w=2-$ classical and rescaled vegetation cases) } \\
\hline$h_{\mathrm{t}}$ & 7.5 & 7.5 & 7.5 & 7.5 & 7.5 & 7.5 & 5.0 & 7.5 & 5.0 & 7.5 & 7.5 & 5.0 & 5.0 \\
\hline$h_{\mathrm{tk}}$ & 2.5 & 2.5 & 2.5 & 2.5 & 2.5 & 5.0 & 2.5 & 5.0 & 2.5 & 5.0 & 5.0 & 2.5 & 2.5 \\
\hline $\mathrm{LAI}_{\mathrm{t}}$ & 1 & 1 & 1 & 1 & 1 & 1 & 1 & 1 & 1 & 1 & 1 & 1 & 1 \\
\hline$\tau_{\mathrm{sr}}$ & 0.5 & 0.5 & 0.5 & 0.5 & 0.5 & 0.5 & 0.5 & 0.5 & 0.5 & 0.5 & 0.5 & 0.5 & 0.5 \\
\hline$\alpha_{\mathrm{r}}$ & 0.25 & 0.25 & 0.25 & 0.25 & 0.25 & 0.25 & 0.25 & 0.25 & 0.25 & 0.25 & 0.25 & 0.25 & 0.25 \\
\hline$\alpha_{\mathrm{w}}$ & 0.30 & 0.30 & 0.30 & 0.30 & 0.30 & 0.30 & 0.30 & 0.30 & 0.30 & 0.30 & 0.30 & 0.30 & 0.30 \\
\hline$\alpha_{\mathrm{t}}$ & 0.25 & 0.25 & 0.25 & 0.25 & 0.25 & 0.25 & 0.25 & 0.25 & 0.25 & 0.25 & 0.25 & 0.25 & 0.25 \\
\hline
\end{tabular}

the urban canyon form, as well as the height of trees and trunks, are comparable to those of SOLENE simulations. But the different spatial arrangements of trees simulated by SOLENE are simply prescribed as cover fractions in TEB. As a result, some configurations (e.g., B1 and B2 with different horizontal locations or B3 and B4 with different numbers of tree lines, shown in Fig. 3) cannot be distinguished by the TEB approach, and are associated with the same cumulative cover fraction of tree canopy in TEB. In this manner, interactions between tree lines are not taken into account in TEB, contrary to SOLENE, where rays are attenuated at each time they cross a mesh belonging to a vegetated envelope. All geometric features of both sets of simulations with SOLENE and TEB are summarized in Table 2. In SOLENE, the incident radiation is roughly attenuated by $50 \%$ once it crosses a mesh which belongs to a vegetation envelope. In terms of process modeling, the formulation of transmissivity of radiation through the foliage in TEB is simplified here for the evaluation stage. In order to be consistent with the SOLENE approach, the exponential attenuation expressing a maximum interception (including the leaf area index) in Eqs. (3), (4), and (5) is replaced by 0.5 . The same way, the formulation proposed in Appendix B (Eqs. B1, B2, B3, and B4) for modulating the radiation attenuation depending on the likely path of rays and based on the leaf area density profile, is substituted here by the expression $1-0.5(\mathrm{LAD} / \mathrm{LAI})$, so that the maximum attenuation is 0.5 when all thickness of tree canopy is passed through. Note also that TEB is forced by the same conditions of incoming solar radiation than those calculated for the roofs in SOLENE. Using a unique forcing for each component (direct or diffuse) of the solar radiation from the SOLENE simulations, TEB forcings do not take into account the non-uniform distribution of incoming diffuse solar radiation. From this imprecision differences result from 1 to $4 \%$ between the fluxes of the two walls, de- pending on their orientation, for studied aspect ratios during summertime (sensitive analysis not shown).

\subsubsection{Comparison method}

Finally, 880 solar radiation simulations are performed with both TEB and SOLENE models. For each of them, hourly outputs are stored. They include the direct and diffuse solar radiation received by the separated elements (road, walls, and tree) before multiple reflections, as well as the total shortwave radiation absorbed by the separate elements after multiple reflections. The main objective of the comparative exercise is to evaluate the cover fraction approach of TEB against a model (SOLENE) resolving the urban radiation budget at fine scale and with trees explicitly represented by geometrical elements. For this purpose, gaps between the simulations of received direct or diffuse solar radiation fluxes by canyon surfaces have been investigated. During multiple reflections, the radiation is assumed to be isotropic in both TEB and SOLENE models. Reflections from the high vegetation in TEB are also omnidirectional but just constrained upwards (in other words, they are based on $\pi$ ) in order to represent more realistically the first and, by far, the most energetic reflection (see details in Sect. 4.4 and Appendix C). To compare the simulations of these two models, only the central part of the SOLENE's mockup is used in order to avoid any boundary effects (see the scheme in Fig. 3). For each flux, the values calculated by SOLENE are summed over all grid points that compose each element of the canyon (separately, the road, the two walls, and the trees). Finally, for both models, the fluxes are weighted to be expressed according to the total ground-based surface of the canyon, so that they can be compared to each other and compared to the incoming radiation. Note that tables with statistical scores presented hereafter have been fulfilled with the same procedure, i.e., the mean absolute difference (MAD in $\mathrm{W} \mathrm{m}^{-2}$ ), the mean absolute percentage difference (MAPD in \%) computed from 
Table 3. Statistical scores for absorbed shortwave radiation flux by surfaces regarding the seasons.

\begin{tabular}{|c|c|c|c|c|c|c|c|c|c|c|c|c|}
\hline \multirow[b]{2}{*}{$\begin{array}{l}\text { Config.-surf. } \\
\text { Units }\end{array}$} & \multicolumn{3}{|c|}{ Winter } & \multicolumn{3}{|c|}{ Spring } & \multicolumn{3}{|c|}{ Summer } & \multicolumn{3}{|c|}{ Autumn } \\
\hline & $\begin{array}{r}\text { MAD } \\
\mathrm{W} \mathrm{m}^{-2}\end{array}$ & $\begin{array}{r}\text { MAPD } \\
\%\end{array}$ & $\begin{array}{r}\text { Bias } \\
\mathrm{W} \mathrm{m}^{-2}\end{array}$ & $\begin{array}{r}\text { MAD } \\
\mathrm{W} \mathrm{m}^{-2}\end{array}$ & $\begin{array}{r}\text { MAPD } \\
\%\end{array}$ & $\begin{array}{r}\text { Bias } \\
\mathrm{W} \mathrm{m}^{-2}\end{array}$ & $\begin{array}{r}\text { MAD } \\
\mathrm{W} \mathrm{m}^{-2}\end{array}$ & $\begin{array}{r}\text { MAPD } \\
\%\end{array}$ & $\begin{array}{r}\text { Bias } \\
\mathrm{W} \mathrm{m}^{-2}\end{array}$ & $\begin{array}{r}\text { MAD } \\
\mathrm{W} \mathrm{m}^{-2}\end{array}$ & $\begin{array}{r}\text { MAPD } \\
\%\end{array}$ & $\begin{array}{r}\text { Bias } \\
\mathrm{W} \mathrm{m}^{-2}\end{array}$ \\
\hline \multicolumn{13}{|l|}{ No vegetation } \\
\hline Road & 2.13 & 43 & +2.02 & 7.45 & 18 & +4.47 & 6.03 & 3 & +3.50 & 5.35 & 17 & +4.21 \\
\hline Walls & 0.81 & 4 & +0.42 & 2.99 & 2 & +0.91 & 3.38 & 3 & +2.80 & 1.86 & 2 & +1.06 \\
\hline \multicolumn{13}{|l|}{ All } \\
\hline Road & 2.67 & 108 & +2.63 & 10.32 & 63 & +9.22 & 16.31 & 24 & +15.56 & 9.46 & 63 & +9.07 \\
\hline Walls & 1.75 & 13 & +1.58 & 6.34 & 13 & +4.77 & 9.39 & 14 & +8.15 & 5.82 & 13 & +4.86 \\
\hline Tree & 3.13 & 53 & -1.20 & 12.15 & 31 & -7.29 & 21.12 & 21 & -15.96 & 12.03 & 31 & -7.31 \\
\hline
\end{tabular}

the mean daily fluxes, and the mean bias (bias in $\mathrm{W} \mathrm{m}^{-2}$ ), according to following equations:

$\mathrm{MAD}=$

$\frac{\sum_{i=1}^{n_{\mathrm{s}}} \sum_{j=1}^{n_{\mathrm{o}}} \sum_{k=1}^{n_{\mathrm{h}}} \sum_{l=1}^{n_{\mathrm{t}}}\left|F_{\mathrm{SOL}}(i, j, k, l)-F_{\mathrm{TEB}}(i, j, k, l)\right|}{n_{\mathrm{s}} \cdot n_{\mathrm{o}} \cdot n_{\mathrm{h}} \cdot n_{\mathrm{t}}}$

MAPD $=$

$100 \cdot \frac{\sum_{i=1}^{n_{\mathrm{S}}} \sum_{j=1}^{n_{\mathrm{o}}} \sum_{k=1}^{n_{\mathrm{h}}}\left|\frac{\overline{F_{\mathrm{SOL}}(i, j, k)}-\overline{F_{\mathrm{TEB}}(i, j, k)}}{\overline{F_{\mathrm{SOL}}(i, j, k)}}\right|}{n_{\mathrm{S}} \cdot n_{\mathrm{O}} \cdot n_{\mathrm{h}}}$

Bias $=$

$\frac{\sum_{i=1}^{n_{\mathrm{s}}} \sum_{j=1}^{n_{\mathrm{o}}} \sum_{k=1}^{n_{\mathrm{h}}} \sum_{l=1}^{n_{\mathrm{t}}}\left(F_{\mathrm{SOL}}(i, j, k, l)-F_{\mathrm{TEB}}(i, j, k, l)\right)}{n_{\mathrm{s}} \cdot n_{\mathrm{o}} \cdot n_{\mathrm{h}} \cdot n_{\mathrm{t}}}$.

The indexes $i, j, k, l$ refer to as season, street orientation, aspect ratio of the street, and hour of the day, respectively, with $n_{\mathrm{s}}=4, n_{\mathrm{o}}=4, n_{\mathrm{h}}=3, n_{\mathrm{t}}=24$. We also run simulations of the $h / w=2$ additional cases where canyons are greened with a rescaled vegetation (see Sect. 5.2.1 and Fig. 2).

\section{Results}

\subsection{General analysis and seasonal effects}

Table 3 presents the statistical scores computed for the shortwave radiation absorbed by the different elements of the canyon for both cases (with and without vegetation). Since multiple reflections are treated differently between TEB and SOLENE, these results are used to show the magnitude of variability of differences related to the presence of vegetation in the canyon or the considered season. Results are presented here by gathering the experiments performed with different street orientations and different vegetation layouts, but by distinguishing the seasons. In the light of the mean biases, the TEB model tends to systematically overestimate the absorption by road and walls compared to SOLENE (up to +16 and $+8.5 \mathrm{~W} \mathrm{~m}^{-2}$ for road and walls, respectively), and to un- derestimate the absorption by trees (up to $-16 \mathrm{~W} \mathrm{~m}^{-2}$ ), regardless of the configuration or the season. Considering that the temperate climate is characterized by four distinct seasons with contrasting sunshine, air temperature, and humidity conditions, seasonal analysis was undertaken. Analysis of the results for each season separately indicates that relative differences (MAPD) are particularly high for wintertime simulations for road and trees, due to a very low incoming solar radiation in that period. Nonetheless, the associated MAD and biases are acceptable (less than 3.5 and $\pm 3 \mathrm{~W} \mathrm{~m}^{-2}$, respectively). Summer is the season which provides the best results in terms of MAPD when the canyon is tree filled (less than $25 \%$ ) or not ( $3 \%$ ). This season is also the most relevant to be examined here because our first concern is to improve the simulation of the potential cooling effect of street trees in a urban environment, submitted to a strong urban heat island at this period. The evaluation is focused on effects of deciduous trees which are typical and widely present in cities under temperate climate. Such trees are leafless during winter, so that they have a negligible impact on thermal comfort and energy demand in this season. That is why we focus on the summertime example hereafter, to assess the TEB performances for simulating the solar radiative exchanges in idealized canyons, vegetated or not.

\subsection{The case of urban canyons without vegetation}

The radiative calculations in TEB are first evaluated for the cases without vegetation. Several comparisons with observations of radiation fluxes at neighborhood scale have been performed (Masson et al., 2002; Lemonsu et al., 2004, 2010; Pigeon et al., 2008). They have shown a good capacity of the model in computing the upward shortwave and longwave radiation at the top of the urban canopy, in real case configurations. But these evaluation exercises have not allowed us to analyze separately the radiative contributions of various elements that compose the urban environment. Such a model-model comparison in a controlled framework is ideal to deeply investigate and evaluate the TEB radiation parameterizations. 
(a) Direct solar radiation received by surfaces
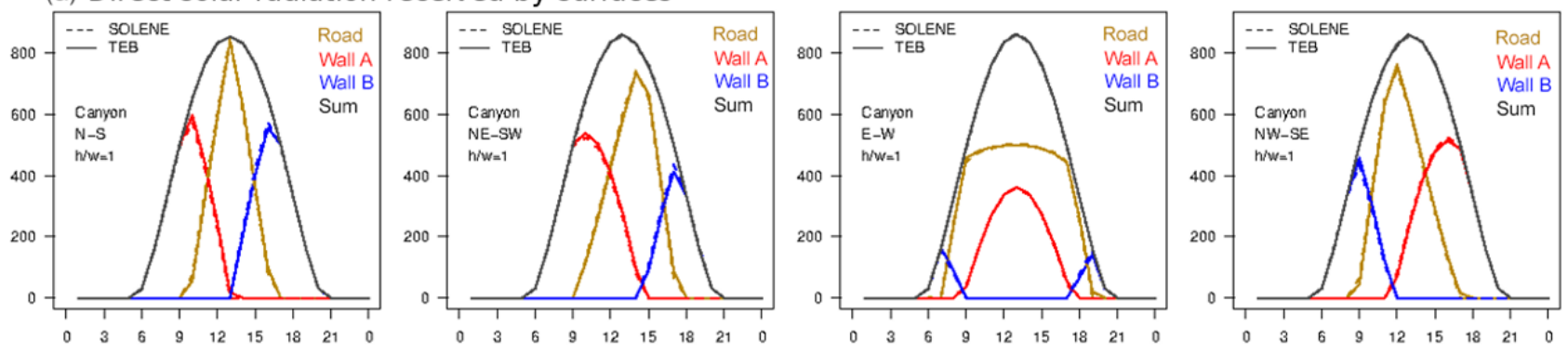

(b) Diffuse solar radiation received by surfaces
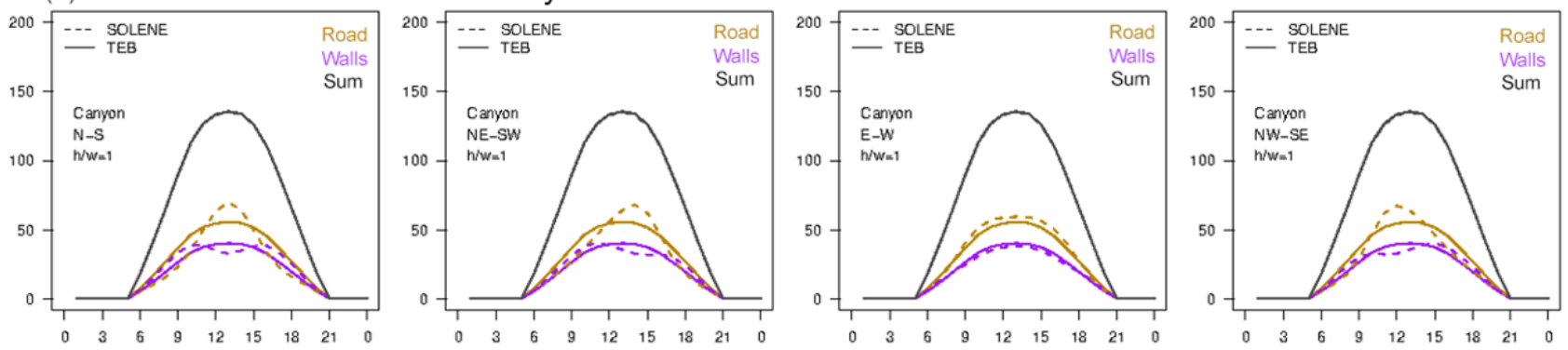

(c) Total solar radiation absorbed by surfaces
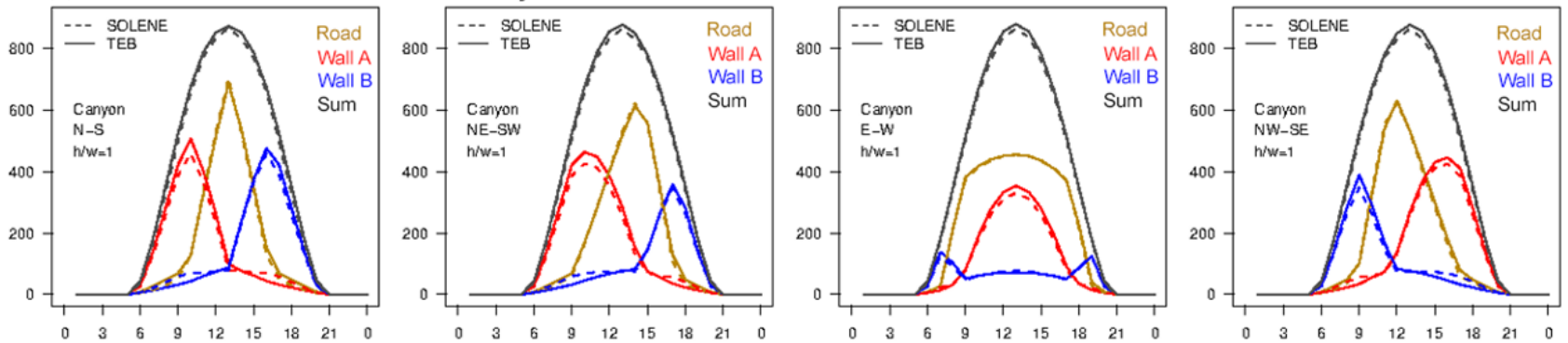

Figure 4. Comparison of TEB and SOLENE simulations of hourly direct (top) and diffuse (middle) solar radiation fluxes (W $\mathrm{m}^{-2}$ ) received by urban facets before multiple reflections, and total shortwave radiation fluxes $\left(\mathrm{W} \mathrm{m}^{-2}\right)$ absorbed by urban facets after inter-reflections (bottom) for urban canyons without vegetation. The results are presented here only for the aspect ratio equal to 1 and for the four street orientations during a summer day.

Both direct and diffuse solar radiation received by the road and the separate walls before any reflections, as well as the total shortwave radiation absorbed by these surfaces, are studied. An example of daily cycle is presented in Fig. 4 for the case where $h / w=1$ and the four street orientations, for the summer season. The scatterplots integrate all the hourly fluxes simulated for the three aspects ratios, the four street orientations, and the four seasons (Fig. 5). As expected, they demonstrate a strong positive linear relationship between fluxes calculated by SOLENE and TEB $\left(R^{2} \geq 0.99\right.$ except for diffuse solar radiation absorbed by roads: $R^{2}=0.979$ ) despite various meteorological conditions.

The comparison between SOLENE and TEB simulations for the direct solar radiation received by road and walls before any reflections highlights very good results. TEB is able to reproduce the geometrical effects of the canyon on radiation penetration according to the time of the day, as well as the street orientation. For northeast-southwest and northwest-southeast-oriented streets, TEB correctly simu- lates the dissymmetry of fluxes between the two walls, as well as the temporal shift in peak of radiation received by the road in comparison with the north-south-oriented street. For the east-west street case, the direct radiation received by the road is marked by a plateau effect between 08:00 and 19:00 LT. The two walls have different behaviors: the wall most exposed to the sun receives the maximum direct radiation at solar noon, whereas the most shaded wall receives direct radiation only early in the morning and late in the afternoon. The scores confirm the good performances of TEB: MAD are 4.39 and $2.49 \mathrm{~W} \mathrm{~m}^{-2}$, and biases are -0.28 and $+0.40 \mathrm{~W} \mathrm{~m}^{-2}$ for road and walls, respectively (Table 4 ). They are associated with low MAPD of only $1 \%$ for both road and walls.

In the calculation of diffuse solar radiation, TEB does not consider the two walls separately. Therefore, the diffuse solar radiation flux is compared between the composite wall of TEB and the average of the diffuse solar radiation fluxes received by separate walls of the SOLENE simulations (Fig. 4). 
(a) Direct solar radiation received by surfaces
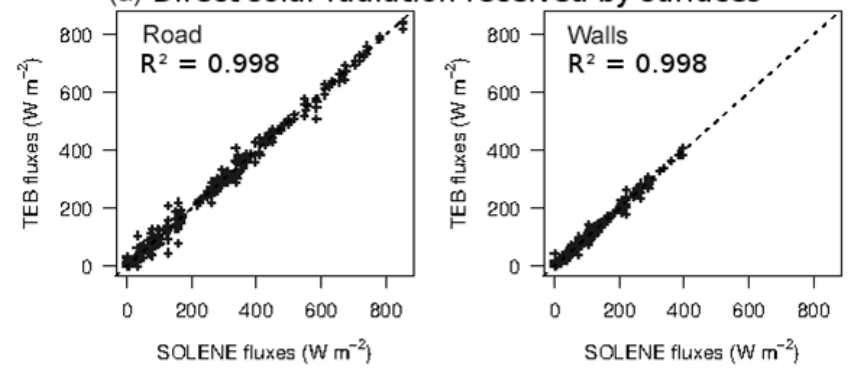

(b) Diffuse solar radiation received by surfaces
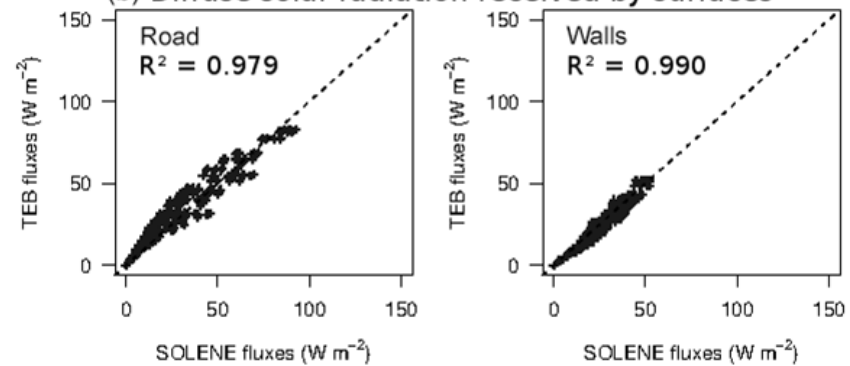

(c) Total solar radiation absorbed by surfaces
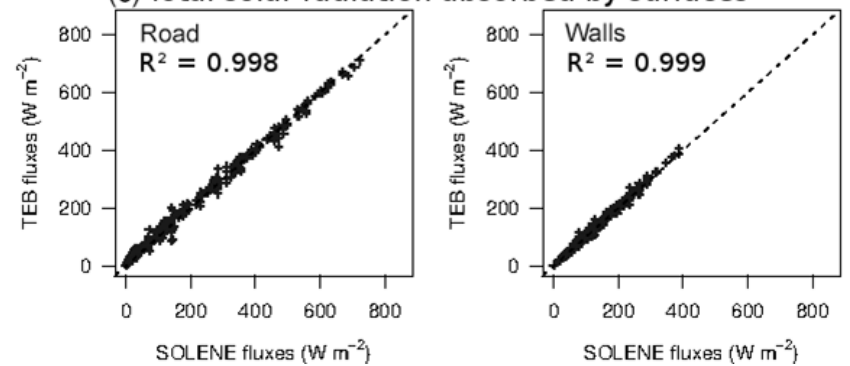

Figure 5. Scatterplots comparing TEB and SOLENE simulations of hourly direct (top) and diffuse (middle) solar radiation fluxes $\left(\mathrm{W} \mathrm{m}^{-2}\right)$ received by urban facets before multiple reflections, and total shortwave radiation fluxes $\left(\mathrm{W} \mathrm{m}^{-2}\right)$ absorbed by urban facets after inter-reflections (bottom) for urban canyons without vegetation. Each scatterplot gathers the hourly fluxes simulated for the four seasons, the three aspect ratios, and the four street orientations.

By considering an average surface, TEB underestimates the diffuse solar radiation received by walls in the morning and the afternoon, and it overestimates it at solar noon. On the contrary, it overestimates the diffuse solar radiation received by the road in the morning and the afternoon, and it underestimates it at solar noon. In this case, MAD and biases remain weak (less than 3.5 and $\pm 1 \mathrm{~W} \mathrm{~m}^{-2}$, respectively) because the involved fluxes are not very high (depending on the season, the diffuse component is only $15-25 \%$ of the total incident solar radiation), but MAPD values are slightly higher than for direct solar radiation, reaching 7 and $5 \%$ for road and walls, respectively (Table 5). However, these discrepancies have no impact on performances of TEB neither at daily scale on fluxes of walls nor on instantaneous cumulated canyon fluxes. Moreover, the dissymmetry of received diffuse solar radiation fluxes is no longer observed in east-west-oriented cases.

Finally, the total shortwave radiation absorbed by road and walls is well estimated by TEB despite the simplified hypotheses of the model and the use of a unique sky view factor by the surface: MAD and biases are 6.03 and $+3.50 \mathrm{~W} \mathrm{~m}^{-2}$ for road, respectively, and 3.38 and $+2.80 \mathrm{~W} \mathrm{~m}^{-2}$ for walls (Table 6). In view of the important incident radiation flux, exceeding $1000 \mathrm{~W} \mathrm{~m}^{-2}$ at solar noon, the MAPD of $3 \%$ for both surfaces remains moderate.

\subsection{The case of urban canyons with vegetation}

The same evaluations are conducted for vegetated canyons. The statistical scores are computed as previously (see Eqs. 20, 21, 22) but by accounting for the 13 vegetation layouts. We also computed additional cases of vegetation layouts for the configurations referred to as " $h / w=2$ rescaled vegetation" (see Sect. 5.2.1 and Fig. 2 for further explanations). As an example, a comparison of hourly fluxes is presented in Fig. 6 for the layout A and an aspect ratio $h / w=1$, and for the summer daily cycle. This configuration is one of the most simple and comparable layouts between the two models: trees are $7.5 \mathrm{~m}$ high (i.e., almost the same height as buildings), tree crowns have a $5 \mathrm{~m}$ thickness; they are centered in the middle of the canyon and cover $90 \%$ of the canyon width on the horizontal plane.

The daily evolution of direct solar radiation received by the different elements of the canyon can be compared to the case without vegetation (Fig. 4). The same patterns are obtained, whether for walls or road and the four street orientations, with an attenuation due to the presence of trees. Here, a significant part of direct incoming solar radiation is intercepted by the foliage. Due to its partial transparency properties, the foliage allows at least half of radiation fluxes to pass through (see Sect. 5.2.2). As a result, the urban surfaces (walls and road) receive less incoming direct radiation but are never totally obstructed by trees. These processes are correctly simulated by TEB with some limitations: due to the expression of direct solar radiation intercepted by high vegetation at the top of the crown, which is treated as a horizontal surface in TEB (Eq. 1), the fluxes reaching the trees in TEB are globally underestimated compared to the SOLENE fluxes that include contributions on the vertical faces of the crown envelope (Fig. 7a, all seasons and configurations). Consequently, the solar radiation which is not intercepted by the tree layer in TEB simulations is assigned to the road and the bottom of walls. This leads for the configuration A to MAD values of 9.27, 3.52, and $6.22 \mathrm{~W} \mathrm{~m}^{-2}$ for road, walls, and trees, respectively, and MAPD values of 14,5 , and $4 \%$ only (Table 4 ). The thicker the crown, the greater the difference associated with the tree (D1 vs. B1 or D2 vs. B2), particularly when the 
Table 4. Statistical scores for direct solar radiation received by surfaces before multiple reflections for summertime.

\begin{tabular}{lrrr|rrr|rrr}
\hline & \multicolumn{3}{c|}{ Road } & \multicolumn{3}{c}{ Walls } & \multicolumn{3}{c}{ Tree } \\
\cline { 2 - 9 } Config. & $\begin{array}{r}\mathrm{MAD}^{-2} \\
\text { Units }\end{array}$ & $\begin{array}{r}\mathrm{W} \mathrm{m}^{-2} \\
\text { NAP }\end{array}$ & $\begin{array}{r}\text { Bias } \\
\mathrm{W} \mathrm{m}^{-2}\end{array}$ & $\begin{array}{r}\text { MAD } \\
\mathrm{W} \mathrm{m}^{-2}\end{array}$ & $\begin{array}{r}\text { MAPD } \\
\%\end{array}$ & $\begin{array}{r}\text { Bias } \\
\mathrm{W} \mathrm{m}^{-2}\end{array}$ & $\begin{array}{r}\text { MAD } \\
\mathrm{W} \mathrm{m}^{-2}\end{array}$ & $\begin{array}{r}\text { MAPD } \\
\%\end{array}$ & $\begin{array}{r}\text { Bias } \\
\mathrm{W} \mathrm{m}^{-2}\end{array}$ \\
\hline No veg. & 4.39 & 1 & -0.28 & 2.49 & 1 & +0.40 & - & - & - \\
A & 9.27 & 14 & +8.73 & 3.52 & 5 & -1.55 & 6.22 & 4 & -5.43 \\
B1 & 11.01 & 9 & +9.11 & 10.84 & 6 & +2.12 & 19.22 & 32 & -13.17 \\
B2 & 23.09 & 26 & +22.51 & 8.26 & 8 & +2.25 & 27.71 & 37 & -26.76 \\
B3 & 16.77 & 22 & +16.47 & 11.25 & 20 & +10.14 & 37.07 & 30 & -36.78 \\
B4 & 20.80 & 29 & +20.42 & 7.09 & 8 & -0.94 & 19.44 & 17 & -18.35 \\
C1 & 9.10 & 14 & +8.55 & 3.51 & 5 & -1.57 & 5.96 & 4 & -5.18 \\
C2 & 13.81 & 21 & +13.47 & 5.89 & 9 & -4.98 & 4.13 & 3 & -3.17 \\
C3 & 8.39 & 9 & +7.79 & 9.77 & 16 & +8.67 & 25.58 & 22 & -25.24 \\
C4 & 11.58 & 13 & +11.15 & 4.77 & 4 & +1.58 & 14.13 & 18 & -13.91 \\
D1 & 11.38 & 6 & +6.40 & 10.03 & 5 & +1.29 & 14.95 & 29 & -8.86 \\
D2 & 15.84 & 17 & +15.29 & 8.29 & 8 & +2.23 & 20.52 & 30 & -19.56 \\
D3 & 6.17 & 4 & +3.90 & 7.82 & 4 & -1.68 & 15.14 & 20 & -0.21 \\
D4 & 19.38 & 21 & +18.62 & 5.05 & 5 & -3.57 & 14.10 & 23 & -11.11 \\
\hline
\end{tabular}

Table 5. Statistical scores for diffuse solar radiation received by surfaces before multiple reflections for summertime.

\begin{tabular}{lrrr|rrr|rrr}
\hline & \multicolumn{3}{c|}{ Road } & \multicolumn{3}{c}{ Walls } & \multicolumn{3}{c}{ Tree } \\
\cline { 2 - 9 } Config. & $\begin{array}{r}\text { MAD } \\
\text { Units }\end{array}$ & $\begin{array}{r}\text { MAPD } \\
\mathrm{W} \mathrm{m}^{-2}\end{array}$ & $\begin{array}{r}\text { Bias } \\
\%\end{array}$ & $\begin{array}{r}\text { MAD } \\
\mathrm{W} \mathrm{m}^{-2}\end{array}$ & $\begin{array}{r}\text { MAPD } \\
\mathrm{W} \mathrm{m}^{-2}\end{array}$ & $\begin{array}{r}\text { Bias } \\
\%\end{array}$ & $\begin{array}{r}\text { MAD } \\
\mathrm{W} \mathrm{m}^{-2}\end{array}$ & $\begin{array}{r}\text { MAPD } \\
\mathrm{W} \mathrm{m}^{-2}\end{array}$ & $\begin{array}{r}\text { Bias } \\
\mathrm{W} \mathrm{m}^{-2}\end{array}$ \\
\hline No veg. & 3.35 & 7 & +0.87 & 1.70 & 5 & -0.43 & - & - & - \\
A & 1.91 & 15 & +1.37 & 1.51 & 9 & +1.07 & 3.51 & 20 & -3.50 \\
B1 & 2.99 & 14 & +1.91 & 1.83 & 8 & +1.09 & 4.10 & 43 & -4.10 \\
B2 & 4.03 & 29 & +3.79 & 1.64 & 7 & +0.79 & 5.38 & 49 & -5.38 \\
B3 & 3.10 & 24 & +2.75 & 2.88 & 27 & +2.72 & 8.22 & 44 & -8.22 \\
B4 & 3.37 & 30 & +3.21 & 1.47 & 6 & +0.74 & 4.71 & 32 & -4.71 \\
C1 & 1.89 & 14 & +1.31 & 1.50 & 11 & -0.55 & 1.73 & 13 & -0.24 \\
C2 & 1.90 & 14 & +1.35 & 1.60 & 4 & -0.19 & 1.94 & 12 & -0.88 \\
C3 & 2.43 & 13 & +1.52 & 1.69 & 12 & +1.38 & 4.36 & 28 & -4.36 \\
C4 & 2.37 & 13 & +1.50 & 1.69 & 5 & +0.52 & 2.61 & 22 & -2.47 \\
D1 & 2.82 & 10 & +1.31 & 1.53 & 3 & +0.36 & 2.05 & 26 & -2.05 \\
D2 & 3.27 & 20 & +2.73 & 1.40 & 5 & +0.25 & 3.25 & 35 & -3.25 \\
D3 & 2.80 & 9 & +1.10 & 1.63 & 3 & -0.11 & 1.20 & 17 & -0.86 \\
D4 & 3.54 & 22 & +3.07 & 1.62 & 5 & -0.65 & 1.84 & 27 & -1.72 \\
\hline
\end{tabular}

tree rows are away from the walls (B1 vs. B2, D1 vs. D2, or D3 vs. D4), contrary to a continuous tree layer occupying almost the entire width of the canyon (A, C1, C2).

As expressed in Eqs. (9) and (10), the diffuse solar radiation fluxes received by road and walls (walls are managed together as an average surface), depends on the sky view factor of the given surface and on an attenuation coefficient of the incoming radiation through the foliage. Regarding all seasons and configurations combined, the received solar radiation by ground-based surfaces is also overestimated while the diffuse solar radiation flux reaching tree crowns is underestimated in the TEB simulations (Fig. 7b). Remember that the diffuse solar radiation received by the trees is calcu- lated in TEB as the residual part of the incoming diffuse solar radiation flux which was not received by road and walls (see Eq. 11). Contrasted results are obtained for the vertical surfaces regardless of the vegetation layouts, in particular between double-row or centered trees (B3 vs. B4). As previously discussed in Sect. 5.4, these defects are related to the use of a single sky view factor for each surface, which is computed at mid-height of buildings for walls and in the middle of the street for road. In addition, the isotropic nature of the diffuse solar radiation leads to an exacerbation of the underestimation of the received flux by the high vegetation, particularly in cases where the side surface of vegetation envelopes is larger: for example, thick crowns with longer 
Table 6. Statistical scores for total shortwave radiation absorbed by surfaces after multiple reflections for summertime.

\begin{tabular}{lrrr|rrr|rrr}
\hline & \multicolumn{3}{c|}{ Road } & \multicolumn{3}{c}{ Walls } & \multicolumn{3}{c}{ Tree } \\
\cline { 2 - 9 } Config. & $\begin{array}{r}\mathrm{MAD}^{-2} \\
\text { Units }\end{array}$ & $\begin{array}{r}\text { MAPD } \\
\mathrm{W} \mathrm{m}^{-2}\end{array}$ & $\begin{array}{r}\text { Bias } \\
\mathrm{W} \mathrm{m}^{-2}\end{array}$ & $\begin{array}{r}\text { MAD } \\
\mathrm{W} \mathrm{m}^{-2}\end{array}$ & $\begin{array}{r}\text { MAPD } \\
\%\end{array}$ & $\begin{array}{r}\text { Bias } \\
\mathrm{W} \mathrm{m}^{-2}\end{array}$ & $\begin{array}{r}\text { MAD } \\
\mathrm{W} \mathrm{m}^{-2}\end{array}$ & $\begin{array}{r}\text { MAPD } \\
\%\end{array}$ & $\begin{array}{r}\text { Bias } \\
\mathrm{W} \mathrm{m}^{-2}\end{array}$ \\
\hline No veg. & 6.03 & 3 & +3.50 & 3.38 & 3 & +2.80 & - & - & - \\
A & 13.30 & 26 & +12.98 & 9.30 & 17 & +8.84 & 7.76 & 5 & -2.16 \\
B1 & 13.31 & 14 & +11.91 & 11.64 & 15 & +11.19 & 21.15 & 28 & -16.95 \\
B2 & 24.27 & 32 & +23.79 & 10.36 & 12 & +9.61 & 30.82 & 38 & -29.47 \\
B3 & 21.82 & 36 & +21.64 & 21.05 & 45 & +21.04 & 52.46 & 35 & -50.33 \\
B4 & 23.13 & 39 & +22.82 & 9.44 & 13 & +7.81 & 20.59 & 17 & -17.28 \\
C1 & 12.04 & 23 & +11.81 & 5.26 & 8 & +3.98 & 6.31 & 5 & -0.61 \\
C2 & 16.15 & 30 & +15.83 & 3.99 & 5 & -1.43 & 8.72 & 7 & +4.08 \\
C3 & 13.23 & 19 & +13.01 & 16.10 & 29 & +16.10 & 40.15 & 29 & -37.89 \\
C4 & 15.95 & 23 & +15.67 & 9.28 & 13 & +9.15 & 24.09 & 21 & -19.77 \\
D1 & 12.45 & 11 & +9.29 & 8.10 & 8 & +6.78 & 14.12 & 24 & -8.65 \\
D2 & 17.19 & 21 & +16.70 & 8.05 & 8 & +6.73 & 20.32 & 27 & -18.57 \\
D3 & 9.09 & 9 & +7.24 & 5.25 & 4 & +4.02 & 14.04 & 14 & +0.11 \\
D4 & 20.06 & 25 & +19.52 & 4.21 & 4 & +2.09 & 13.97 & 22 & -9.95 \\
\hline
\end{tabular}

sides and vegetation layouts including two rows where the number of sides is doubled (A vs. B3, C1 vs. C3). Considering the extremely vegetated canyon A, MAPD values are 15,9 and $20 \%$ for road, walls, and tree, respectively, corresponding to MAD values of $1.91,1.51$, and $3.51 \mathrm{~W} \mathrm{~m}^{-2}$ (Table 5). Globally, the estimation of the diffuse solar radiation received by the road and walls are acceptable regarding the MAPD, which are $\leq 30 \%$. However, the relative differences associated with the tree layer are contrasted (from 12 to $49 \%$ ), depending on the characteristics of the vegetation layout.

For the same configuration, when comparing TEB results to the SOLENE simulations as reference, the total shortwave radiation absorbed by the different elements of the canyon is simulated with correct daily dynamics (Fig. 6). Despite similar temporal behavior of the fluxes, their magnitudes can greatly diverge, especially for the road and tree surfaces with some MAPD values greater than $30 \%$ and some biases greater than $\pm 25 \mathrm{~W} \mathrm{~m}^{-2}$ (Table 6). The global scatterplot (Fig. 7c, all seasons and configurations) confirms the trends previously found and the absorbed flux by the trees is underestimated. The predictability based on SOLENE results is also weaker $\left(R^{2}=0.954\right)$. These poor performances of TEB regarding the statistical scores have to be interpreted with caution. This work aims at evaluating the cost in terms of performances of TEB to simulate a correct allocation of radiative fluxes for each facet of the canyon in spite of a simple geometric approach based on cover fractions and a unique view factor per interaction. For example, the tree fraction is computed as a cumulative fraction of all crowns in the street in TEB. Thus, the interactions between tree lines are not allowed, contrary to those in SOLENE. However, the consequences of some other divergent assumptions can alter TEB scores by the comparison of the absorbed fluxes even if nei- ther one or the other model is the truth (as it would have been in observations), and SOLENE can not be considered as the reference simulation for these points. Indeed, the way to calculate the transmissivity during multiple reflections is dissimilar between the two models (see Sect. 5.2.3). TEB code computes infinite isotropic reflections using a unique view factor for each facet of the canyon and mean radiative transmissivity terms. The formulation of the mean radiative transmissivity terms is based on strong hypotheses on the potential attenuation of rays: they express the ratio between the sector of canyon scanned by the view factor associated with the studied interaction and the thickness of crown contained in this canyon sector (see Appendix B). In addition, reflections from the high vegetation are constrained upwards in TEB (see Sect. 4.4 and Appendix C for full explanations). On the contrary, SOLENE radiative scheme computes isotropic multiple reflections within the canyon for each triangular mesh, using the radiosity method. The vegetation envelopes here are strictly semitransparent because the penetration of light through the foliage can not be modulated by the leaf area density. Whatever the foliage thickness which is crossed, as soon as a ray reaches a cell of vegetation envelope in SOLENE, this radiation is attenuated by half.

Further works (not shown) have investigated the sensitivity of TEB results and performances according to the characteristics of the different vegetation layouts. They do not demonstrate clear and systematic patterns when studying the impact of (1) tree horizontal coverage (or the tree fraction), (2) tree canopy height compared to the building height, and (3) tree location - centered or on the side - in the canyon on the MAD and difference percentages recorded. It could be explained by the interaction between opposite effects regarding the vegetation layout characteristics. 
(a) Direct solar radiation received by surfaces
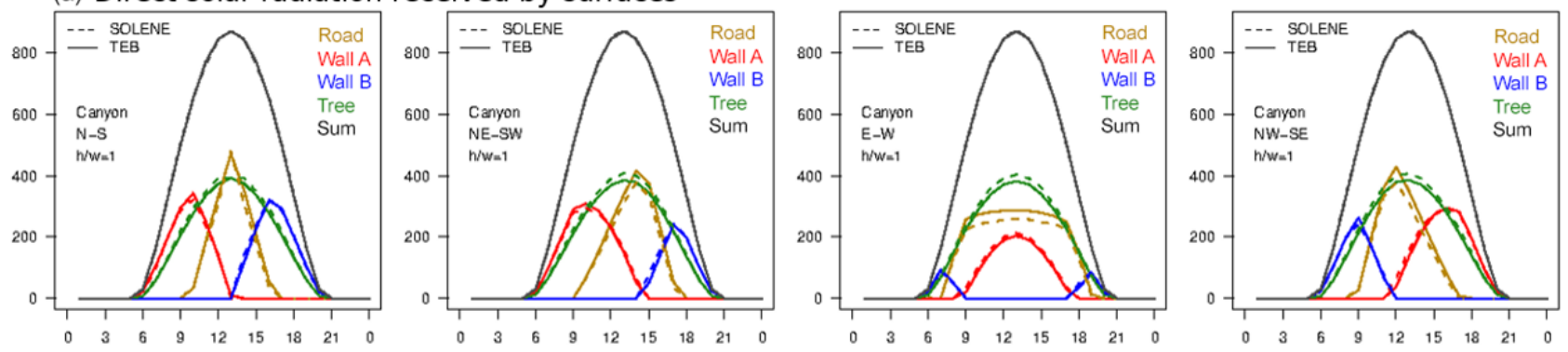

(b) Diffuse solar radiation received by surfaces
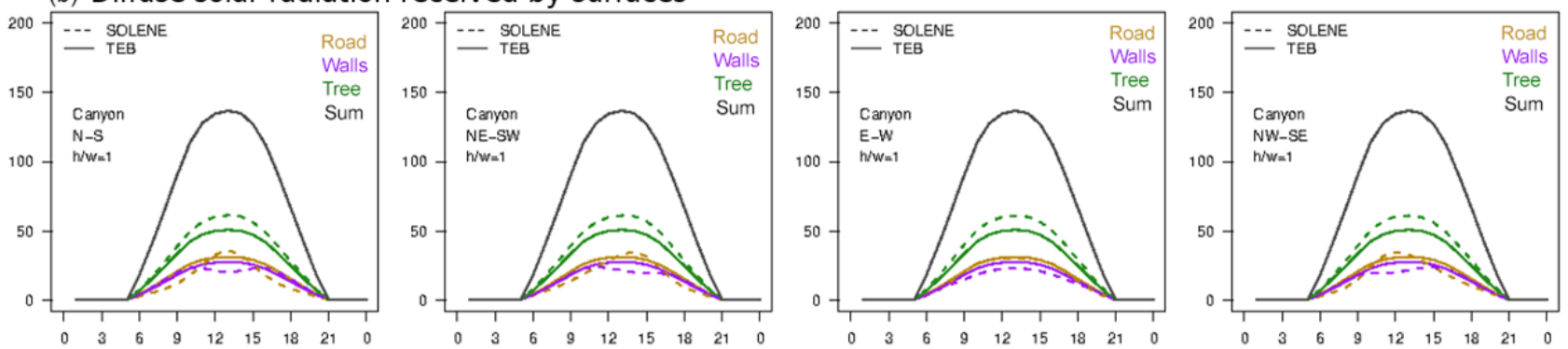

(c) Total solar radiation absorbed by surfaces
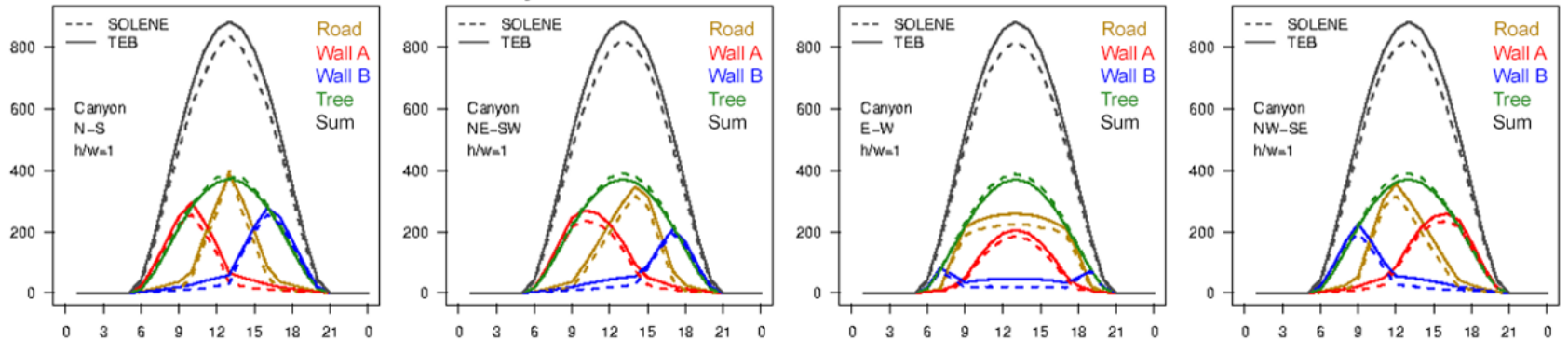

Figure 6. Comparison of TEB and SOLENE simulations of hourly direct (top) and diffuse (middle) solar radiation fluxes $\left(\mathrm{W} \mathrm{m}^{-2}\right.$ ) received by urban facets before multiple reflections, and total shortwave radiation fluxes $\left(\mathrm{W} \mathrm{m}^{-2}\right)$ absorbed by urban facets after inter-reflections (bottom) for urban canyons with vegetation. The results are presented here only for the aspect ratio equal to 1 and for the four street orientations during a summer day.

\subsection{Benefits of TEB developments}

In this section, simulations provided by the initial version of TEB and by the implemented version are compared. For this purpose, we use equations in the new version related to the transmission of radiation fluxes from the high vegetation following the expression presented in Eq. (3), adapted when it required the considered leaf area density (see Appendix B for further details).

\subsubsection{Analysis of the behavior of absorbed shortwave radiation per canyon surface}

The shortwave radiation received and absorbed by the walls and the road can be strongly affected by the presence of tree vegetation. The comparison between the initial version of TEB which deals with vegetation at ground level, and the new version which explicitly includes an additional tree stratum shows differences illustrated in Fig. 8 by taking the ex- ample of a north-south-oriented canyon with an aspect ratio equal to 1 , tree filled by a vegetation layout corresponding to configuration A, during a summer day. Analyzing the fluxes expressed per square meters of the considered surface, artificial surfaces absorb less energy when they are shaded by an explicit tree canopy, while the daily dynamics are similar. At the beginning and the end of the range of lighting hours, trees absorb more energy after the implementation of a real canopy within the canyon instead of initial simulations where the foliage was placed at the ground level. It is explained by the fact that the higher the trees are in the canyon, the more they can receive solar radiation and avoid the shading of buildings. However, around the solar noon, the absorption by the trees is substantially reduced by its transmissivity properties in regards to the initial version where all the urban vegetation surfaces were opaque. As a result, the vegetation absorbs all the solar radiation which is received and not reflected. In the present case, this part is $75 \%$ of the incident solar radiation 
(a) Direct solar radiation received by surfaces
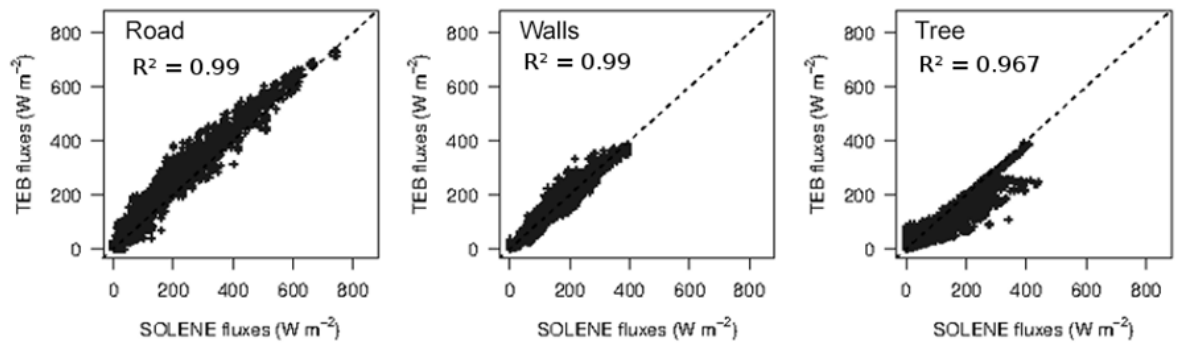

(b) Diffuse solar radiation received by surfaces
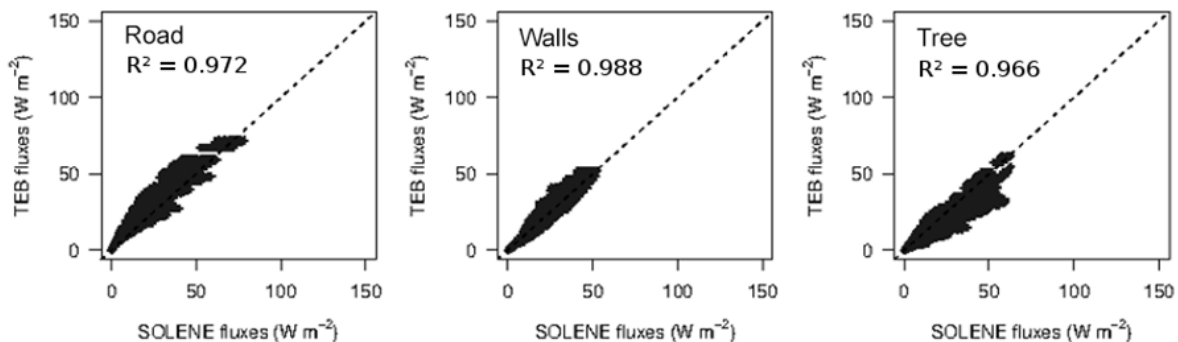

(c) Total solar radiation absorbed by surfaces
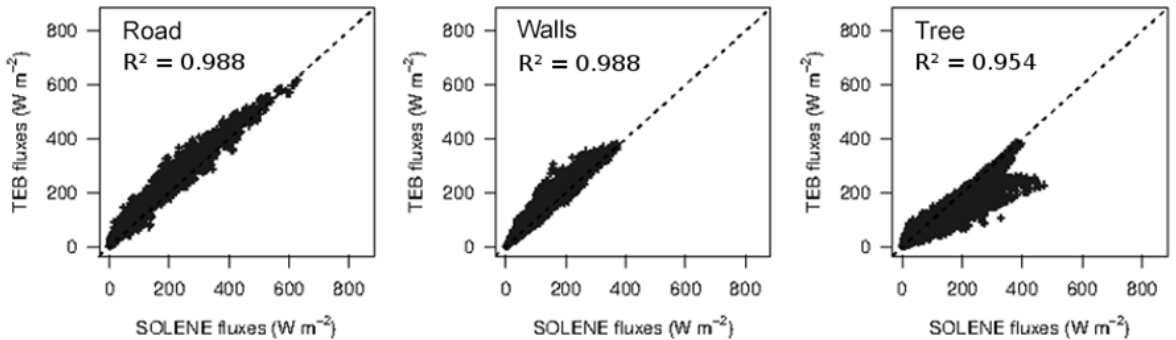

Figure 7. Scatterplots comparing TEB and SOLENE simulations of hourly direct (top) and diffuse (middle) solar radiation fluxes (W $\mathrm{m}^{-2}$ ) received by facets before multiple reflections, and total shortwave radiation fluxes $\left(\mathrm{W} \mathrm{m}^{-2}\right)$ absorbed by facets after inter-reflections (bottom) for urban canyons with vegetation. Each scatterplot gathers the hourly fluxes simulated for the four seasons, the four aspect ratios, and the four street orientations.

since $\alpha_{\mathrm{t}}=0.25$. In the new version, $50 \%$ of the received solar radiation is transmitted through the foliage and $75 \%$ of the remaining flux is absorbed by trees, i.e., only $37.5 \%$ of the total shortwave radiation received by trees.

Comparing the fluxes before and after their weighting based on their canyon fraction, the road absorption by squared meters of canyon can extremely vary following the garden fraction at the ground in the initial version. Indeed, in the reference cases, the high vegetation is treated as a groundbased vegetation fraction which is included in the garden fraction $\left(\delta_{\mathrm{g}}\right)$. This limitation implies that the garden fraction takes the value of the greater fraction between low and high vegetation. Consequently, the road fraction, which is always defined as $1-\delta_{\mathrm{g}}$, is varying according to the vegetation layout. For example, here, the road fraction is only 0.10 . For this experiment, the differences between before and after the weighting of absorbed fluxes by trees is small because the tree fraction is high $(=0.90)$. In this case, there is no differences for the walls according to the unit of the fluxes since the canyon aspect ratio is $h / w=1$. For smaller aspect ratios, the fluxes of walls based on the canyon surface will be lower than those calculated by squared meters of wall. On the contrary, for aspect ratios exceeding 1, the fluxes of walls based on the canyon surface will be higher. The new developments have corrected a systematic overestimation bias in the reference version. This can have a significant impact on the simulation of thermal comfort conditions for pedestrians as well as on energy consumption of buildings for air-conditioning usage.

\subsubsection{Analysis of an integrated canyon albedo}

The albedo of the canyon $\left(\alpha_{\text {can }}\right)$ is calculated as the ratio between the outgoing shortwave radiation (which is deduced from the difference between the total incoming radiation 

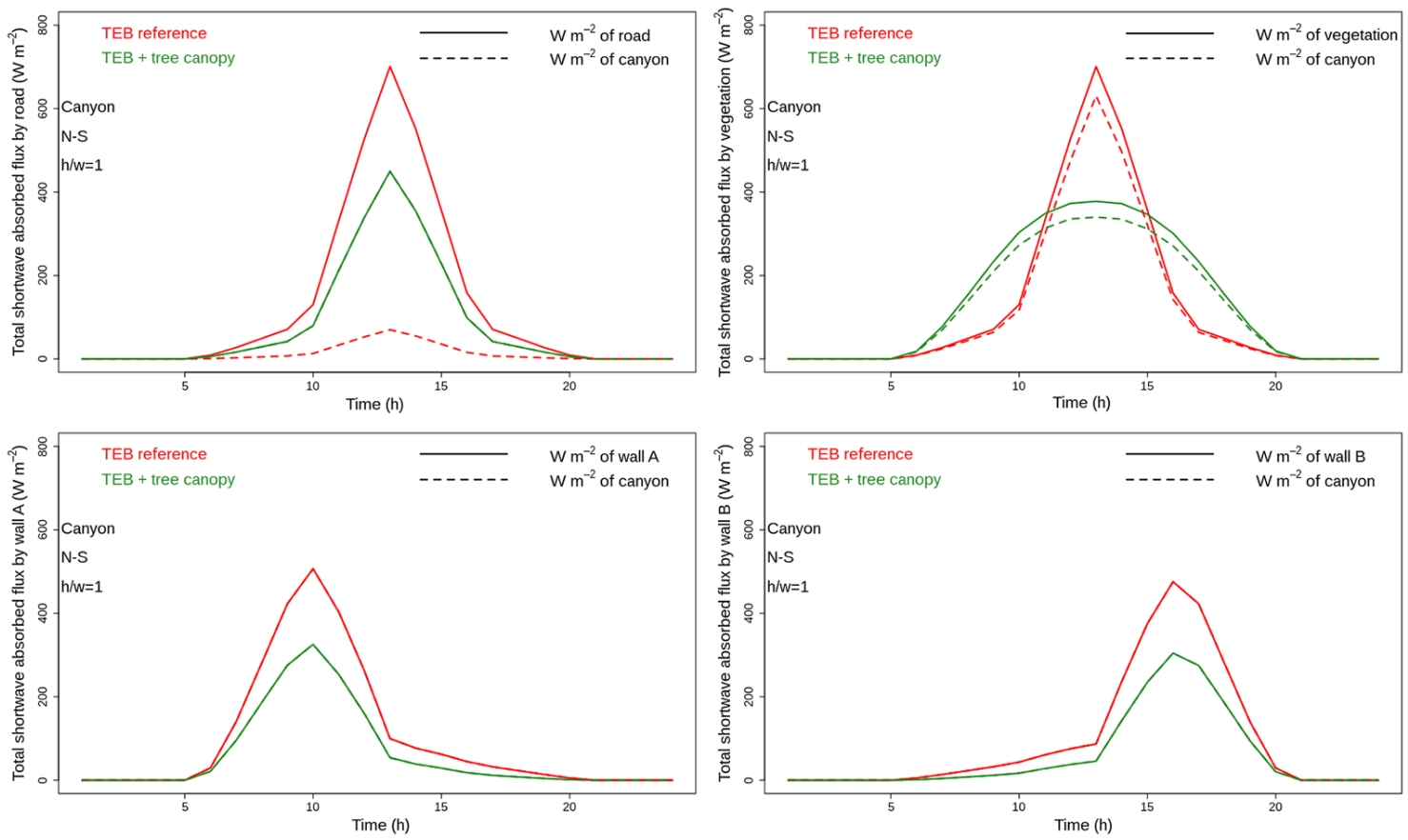

Figure 8. Comparison of the total shortwave radiation flux $\left(\mathrm{W} \mathrm{m}^{-2}\right)$ absorbed by road, walls, and tree between the reference TEB simulations without distinction between low and high vegetation, and the new version including an explicit tree canopy corresponding to configuration A within a north-south-oriented canyon with an aspect ratio of $h / w=1$ during a summer day. The fluxes are expressed either in $\mathrm{W} \mathrm{m}^{-2}$ of the considered surface or in $\mathrm{W} \mathrm{m}^{-2}$ of canyon.

$S_{\text {can }}^{\Downarrow}+S_{\text {can }}^{\downarrow}$ and the absorbed radiation $S_{\text {can }}^{*}$ ) and the total incoming shortwave radiation:

$\alpha_{\mathrm{can}}=\frac{\left(S_{\mathrm{can}}^{\Downarrow}+S_{\mathrm{can}}^{\downarrow}\right)-S_{\mathrm{can}}^{*}}{\left(S_{\mathrm{can}}^{\Downarrow}+S_{\mathrm{can}}^{\downarrow}\right)}$.

For each simulation, these fluxes are used at the solar noon in order to compute an instantaneous canyon albedo. The results in summertime are presented as box plots (Fig. 9) that gather all the vegetation layouts, if any, but that distinguish the canyon aspect ratios. Only north-south canyons are represented here. It is a synthetic indicator of TEB enhancement at the scale of the entire canyon, which is crucial when SURFEX is run coupled with an atmospheric model such as the research MESO-NH model (Lafore et al., 1997) or the operational model AROME (Seity et al., 2011) to provide climatic simulations.

The aspect ratio has a significant impact on the canyon albedo: the canyon albedo decreases with an increasing aspect ratio. Since the geometry and radiative properties of the vegetationless canyons and ground-based vegetation canyons in the reference version of TEB are comparable, they provide similar canyon albedos. It is explained by the absence of foliage in the vertical plane and identical albedos of road and garden $\left(\alpha_{\mathrm{r}}=\alpha_{\mathrm{g}}=0.25\right)$. For canyons with $h / w=0.5$ aspect ratios, the albedo of vegetated canyons with an explicit tree canopy is systematically lower than unobstructed canyons. Trees can more easily absorb the incoming solar radiation than ground-based surfaces. For higher aspect ratios, the impact of trees depends on the balance between their greater sky view factor and reflectivity regarding artificial surfaces and their trapping effect on solar radiation, reducing or increasing the total solar energy absorption by the canyon, respectively. Note also that their relative impact is lower when the thickness of the crown is proportionally small compared to the height of the buildings. For rescaled vegetation cases in deep streets, we observe a greater variability of canyon albedos compared to the same urban form with thinner tree crowns placed in the lower part of the canyon.

\section{Conclusions}

In order to investigate some of the physical processes related to the presence of vegetation in an urban environment, e.g., for microclimate, hydrology, or building energy consumption issues, the modeling is definitely a necessary tool.

The TEB model has been refined and improved in order to explicitly represent street trees and their impacts on radiative transfer. The new parameterization is based on the simple hypotheses of TEB: (1) a little-detailed geometry without specific spatial arrangement of ground-based surfaces and (2) a 


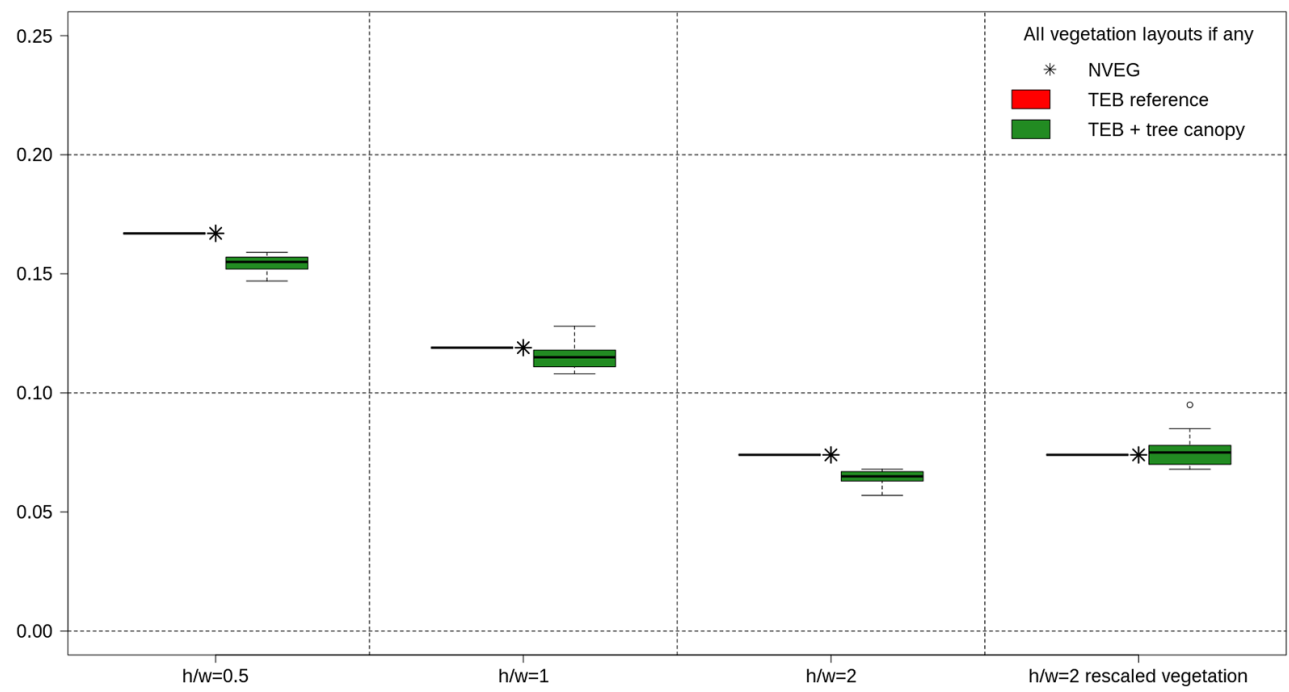

Figure 9. Comparison of the canyon albedo at solar noon between the reference TEB simulations without distinction between low and high vegetation, and the new version including a tree canopy by aspect ratios for all vegetation layouts combined within north-south-oriented canyons during a summer day. See Sect. 5.2.1 and Fig. 2 for further explanations about the $h / w=2$ rescaled vegetation configurations.

single view factor for each emitting and receiving surface applied for radiative calculations.

To take into account the tree canopy in TEB, it was however required to add a new vegetated stratum on the vertical plane, which can shade the road, the walls, and the low vegetation. This modification led to more complex radiative calculations, but has been done with a concern to preserve a certain level of simplicity and to limit the number of new input parameters for TEB. It is important to emphasize that the model is designed to be run over whole cities, for which it can simulate the local climatic variability related to urban landscape heterogeneities at the neighborhood scale. This means that computing times must be acceptable, and that input urban data must be available or easy to define. Consequently, the high vegetation is described here using only five input parameters: cover fraction of trees, height of trees, height of trunks, leaf area index, and albedo.

This simplified characterization of high vegetation necessarily induces some uncertainties on solar radiative exchanges. We estimated it by carrying out a comparative exercise between TEB and a high-spatial-resolution solar and lighting model (SOLENE). On the basis of an idealized geometry of an urban canyon with various vegetation layouts, TEB is evaluated regarding the total shortwave radiation flux absorbed by the elements that compose the canyon. TEB simulations in summer gathered the best scores for all configurations and surfaces considered, which is precisely the most relevant season to assess the cooling effect of deciduous trees under temperate climate. Statistical scores have demonstrated a good capacity of TEB to solve the radiative balance of canyons without vegetation despite the use of a unique sky view factor for each facet of the urban scene. Mean absolute differences and biases of 6.03 and $+3.50 \mathrm{~W} \mathrm{~m}^{-2}$ for road, re- spectively, and of 3.38 and $+2.80 \mathrm{~W} \mathrm{~m}^{-2}$ for walls have been recorded in vegetationless canyons. In view of the important incident radiation flux, exceeding $1000 \mathrm{~W} \mathrm{~m}^{-2}$ at solar noon, the mean absolute percentage differences of $3 \%$ for both surfaces remain moderate. Additionally, it is necessary to put in perspective obtained scores with the fact that they include the error generated by the treatment of walls as a mean wall in TEB in comparison with separate walls in SOLENE considering the diffuse component of the solar radiation. This identified error is no longer existing at the canyon or daily scales. Concerning the vegetated canyons, we noted a high variability of statistical scores depending on the vegetation layout. The greater uncertainties are found for the solar radiation fluxes received and absorbed by the high vegetation. The mean absolute difference averaged over the vegetation configurations during summertime is $21.12 \pm 13.39 \mathrm{~W} \mathrm{~m}^{-2}$ or $20.92 \pm 10.87 \%$ of mean absolute percentage difference for the total shortwave absorption but these scores are associated with acceptable biases: $-15.96 \pm 15.93 \mathrm{~W} \mathrm{~m}^{-2}$. The systematic underestimation of fluxes reaching the new tree stratum is explained by the cover fraction approach in TEB where sides of the crown are not represented. Interactions between potential tree lines or intra-canopy scattering and trapping are also neglected. Presented scores include the effect of divergent approaches in the formulation of the transmission process through trees between TEB and SOLENE even though neither of the two models could be considered as a reference at this stage for this point.

The parameterization of shortwave radiation exchanges within the canyon is now more realistic: shading effects of trees on vertical and ground-based surfaces but also shading effects of buildings on trees are computed. This is achieved by adding a new specific cover fraction describ- 
ing the horizontal extent of high vegetation. Infinite reflections within the canyon are also conditioned to the transmissivity term calculated per pair of exchanging surfaces. This study demonstrated the enhancement of new developments on the computed absorbed shortwave radiation fluxes within the canyon between the former reference version of TEB and the implemented version. In the current version, trees can intercept and absorb the direct solar radiation at the canopy level instead of from the ground. Consequently, the walls and ground are more shaded. High and low vegetation fractions are now explicitly dissociated. The grass and bare soil fractions only contribute to the garden fraction. In this way, the road fraction, defined as $1-\delta_{\mathrm{g}}$, is independent of the tree cover. This implies that the weighting of fluxes at the canyon scale has become realistic. The aspect ratio has a significant impact on the canyon albedo: the canyon albedo decreases with an increasing aspect ratio. For canyons with $h / w=0.5$ aspect ratios, the albedo of vegetated canyons with an explicit tree canopy is systematically lower than unobstructed canyons. Trees within the canyon can more easily absorb the incoming solar radiation than ground-based surfaces. For higher aspect ratios, the impact of trees depends on the balance between their greater sky view factor and reflectivity regarding artificial surfaces and their trapping effect on solar radiation, reducing or increasing the total solar energy absorption by the canyon, respectively. Canyon albedo is also more vegetation responsive for $h / w=1$ urban forms or in cases where $h / w=2$ canyons when the tree crown thickness is scaled regarding the depth of the street.

The future developments will focus on the separate calculation of turbulent energy fluxes for ground-based and high vegetation. The aerodynamic effect of trees on air flow within the canyon should also be parameterized. The adaptation of TEB to trees taller than buildings will broaden the range of potential neighborhoods to which its tree model could be applied. Based on this more sophisticated version of TEB, new impact studies could be conducted and greening adaptation strategies could be evaluated more precisely.

\section{Code availability}

The TEB code is available in open source via the surface modeling platform SURFEX, downloadable at http://www. cnrm-game-meteo.fr/surfex/. This Open-SURFEX will be updated at relatively low frequency (every 3 to 6 months) and developments presented here are not yet included in the last version. If you need more frequent updates, or if you need what is not in Open-SURFEX (DrHOOK, FA/LFI formats, GAUSSIAN grid), we invite you to follow the procedure to open a SVN account and to access real-time modifications of the code (see instructions in the previous link). 


\section{Appendix A: Sky view and view factors}

Sky view factors for road, garden, and wall (Eqs. A1, A2) as well as the view factors between elements remain unchanged in relation to the initial version of the radiative calculations in TEB (described in Masson, 2000 and Lemonsu et al., 2012):

$$
\begin{aligned}
& \Psi_{\mathrm{rs}}=\Psi_{\mathrm{sr}}=\sqrt{\left(\frac{h}{w}\right)^{2}+1-\frac{h}{w}} \\
& \Psi_{\mathrm{wr}}=\Psi_{\mathrm{ws}}=\frac{\frac{1}{2}\left(\frac{h}{w}+1-\sqrt{\left(\frac{h}{w}\right)^{2}+1}\right)}{\frac{h}{w}} \\
& \Psi_{\mathrm{sw}}=1-\Psi_{\mathrm{sr}} \\
& \Psi_{\mathrm{ww}}=1-2 \Psi_{\mathrm{ws}}=\frac{\sqrt{\left(\frac{h}{w}\right)^{2}+1}-1}{\frac{h}{w}} \\
& \Psi_{\mathrm{rw}}=1-\Psi_{\mathrm{rs}}=1-\left(\sqrt{\left(\frac{h}{w}\right)^{2}+1}-\frac{h}{w}\right) .
\end{aligned}
$$

For the tree canopy, the sky view factor and view factors from road and walls are computed in the middle of the canyon and at mid-height of the crown $\left(h_{\mathrm{cw}}\right)$ :

$$
\begin{aligned}
\Psi_{\mathrm{st}} & =\sqrt{\left(\frac{h}{w} \cdot \frac{h-h_{\mathrm{cw}}}{h}\right)^{2}+1}-\left(\frac{h}{w} \cdot \frac{h-h_{\mathrm{cw}}}{h}\right) \\
\Psi_{\mathrm{rt}} & =\sqrt{\left(\frac{h}{w} \cdot \frac{h_{\mathrm{cw}}}{h}\right)^{2}+1}-\left(\frac{h}{w} \cdot \frac{h_{\mathrm{cw}}}{h}\right) \\
\Psi_{\mathrm{wt}} & =1-\frac{1}{2}\left(\Psi_{\mathrm{st}}+\Psi_{\mathrm{rt}}\right) .
\end{aligned}
$$

$\Psi_{\mathrm{st}}$ and $\Psi_{\mathrm{rt}}$ are calculated in the same way as $\Psi_{\mathrm{sr}}$ in the middle of the canyon but they are adjusted to the $\left[h_{\mathrm{cw}}-h\right]$ area and the $\left[0-h_{\mathrm{cw}}\right]$ area, respectively. $\Psi_{\mathrm{wt}}$ is computed as the complementary term of $\Psi_{\mathrm{st}}$ and $\Psi_{\mathrm{rt}}$ on $2 \pi$ and for one wall (as well as $\Psi_{\mathrm{ws}}$ and $\Psi_{\mathrm{ww}}$ ). We normalized $\Psi_{\mathrm{wt}}$ to express it on one $\pi$ only.

\section{Appendix B: Mean radiative transmissivity of canyon tree canopy}

The multiple reflections of solar radiation inside the canyon (as detailed in Masson, 2000 and Lemonsu et al., 2012) are now affected by the presence of trees whose foliage intercepts, reflects, and absorbs a part of the energy. The transmissivity of radiation through the foliage of tree canopy is variable according to the way the rays cross the foliage and the distance they travel. According to the location of tree crowns inside the canyon and the dominant orientation of radiation (e.g., emissions from sky to ground or from wall to ground do not reach the foliage the same way), these rays can cross all the foliage thickness or only a small portion. The vertical distribution of leaves in the tree crowns also has an impact on transmissivity.

Different transmissivity functions (referred to as $\tau_{12}$ for exchanges between element 1 and element 2) are calculated depending of the surfaces involved in radiative exchanges. One distinguishes four cases of radiation exchanges by hypothesizing that transmissivity functions are symmetric; i.e., exchanges from element 1 to element 2 are equivalent to the reverse way: between ground-based surfaces and sky $\left(\tau_{\mathrm{rs}}=\tau_{\mathrm{sg}}\right)$ or wall $\left(\tau_{\mathrm{rw}}=\tau_{\mathrm{gw}}\right)$, between wall and sky $\left(\tau_{\mathrm{ws}}\right)$, and between wall and wall $\left(\tau_{\mathrm{ww}}\right)$. For each case, we admit, according to Lee and Park (2008), that majority of radiation exchanges occur in a specific area of the canyon, for which the leaf area density $\left(\mathrm{LAD}_{\mathrm{t}}\right.$, expressed in $\mathrm{m}^{2}$ of leaf area per $\mathrm{m}^{3}$ of volume) is calculated:

$$
\begin{aligned}
& \tau_{\mathrm{rs}}=1-\delta_{\mathrm{t}}\left[1-\exp \left(-k \int_{0}^{h} \mathrm{LAD}_{\mathrm{t}} \mathrm{d} z\right)\right] \\
& \tau_{\mathrm{rw}}=1-\delta_{\mathrm{t}}\left[1-\exp \left(-k \int_{0}^{\frac{h}{2}} \mathrm{LAD}_{\mathrm{t}} \mathrm{d} z\right)\right] \\
& \tau_{\mathrm{ws}}=1-\delta_{\mathrm{t}}\left[1-\exp \left(-k \int_{\frac{h}{2}}^{h} \mathrm{LAD}_{\mathrm{t}} \mathrm{d} z\right)\right] \\
& \tau_{\mathrm{ww}}=1-\delta_{\mathrm{t}}\left[1-\exp \left(-k \int_{0}^{h} \mathrm{LAD}_{\mathrm{t}} \mathrm{d} z\right)\right] .
\end{aligned}
$$

The limits of integrals involved in the calculation of the transmissivity functions have been consistently defined with canyon sectors scanned by the associated view factors. For example, Eq. (9) expresses how the diffuse incoming solar radiation reaches the road from the sky. This formulation is typically based on the sky view factor of the road $\Psi_{\mathrm{rs}}$ which scans an area covering the entire height of the building. We added a transmissivity function $\tau_{\mathrm{rs}}$ describing the ratio between the thickness of the tree crown within the canyon and the vertical extent of the area of interest, here $[0-h]$.

Note that these expressions are in accordance with the one applied in Eq. (3) in which $\mathrm{LAD}_{\mathrm{t}}$ is integrated on the entire thickness of foliage so that it is equivalent to $\mathrm{LAI}_{\mathrm{t}}$. As mentioned above, since the tree crown is described as a rectangular parallelepiped with a regular distribution of leaves, a uniform vertical profile of LAD is applied here.

\section{Appendix C: Total shortwave radiation absorption by solving infinite reflections}

For solar radiation calculations, the TEB model takes into account an infinite number of reflections between all elements composing the urban canyon. At each reflection, the isotropic radiation intercepted by a given element, (1), after reflections on one of the other elements, (2), is conditioned by the view factor of (2) from (1), referred to as $\Psi_{12}$ (see Appendix A), 
the mean radiative transmissivity $\tau_{12}$ (see Appendix B), and the reflection is then determined according to reflective properties of (1). As seen in the Sect. 4.4, the total shortwave radiation absorbed by each elements of the canyon or redirected towards the sky is a function of infinite reflections $R_{\infty}, G_{\infty}$, $A_{\infty}, B_{\infty}$, and $T_{\infty}$ that are still unknowns at this stage. These terms include the first reflection on each element: $R_{0}, G_{0}$, $A_{0}, B_{0}$, and $T_{0}$. For road, garden, and walls, $R_{0}, G_{0}, A_{0}$, and $B_{0}$ simply depend on the incident solar radiation on the surface and the albedo. From Eqs. (15), (16), (17), (18), and (19), we can deduce the reflected part occurring at the $n+1$ th absorption as the complementary term of the $n+1$ th solar radiation reception for only opaque elements of the canyon, "road", "garden", "wall A", and "wall B", respectively. As examples, we obtain for road and wall A, respectively:

$$
\begin{aligned}
R_{0} & =\alpha_{\mathrm{r}}\left(S_{\mathrm{r}}^{\Downarrow}+S_{\mathrm{r}}^{\downarrow}\right) \\
R_{n+1} & =R_{0}+\alpha_{r}\left[\Psi_{\mathrm{rw}} \tau_{\mathrm{rw}} W_{\mathrm{n}}+c_{\mathrm{rt}} \Psi_{\mathrm{rt}} \delta_{\mathrm{t}} T_{\mathrm{n}}\right] \\
A_{0}= & \alpha_{\mathrm{w}}\left(S_{\mathrm{w}}^{\Downarrow}+S_{\mathrm{w}}^{\downarrow}\right) \\
A_{n+1}= & A_{0}+\alpha_{\mathrm{w}}\left[\Psi_{\mathrm{ww}} \tau_{\mathrm{ww}} B_{\mathrm{n}}+\Psi_{\mathrm{wr}} \tau_{\mathrm{wr}}\right. \\
& \left.\left(\delta_{\mathrm{r}} R_{\mathrm{n}}+\delta_{\mathrm{g}} G_{\mathrm{n}}\right)+c_{\mathrm{wt}} \Psi_{\mathrm{wt}} \delta_{\mathrm{t}} T_{\mathrm{n}}\right] .
\end{aligned}
$$

The specific coefficients associated with the view factors related to the high vegetation in shortwave reflections calculations are defined as

$$
\begin{aligned}
c_{\mathrm{rt}} & =0 \\
c_{\mathrm{wt}} & =\frac{1-\Psi_{\mathrm{st}}}{2-\Psi_{\mathrm{st}}-\Psi_{\mathrm{rt}}} .
\end{aligned}
$$

Only reflections from trees to sky or top part of walls are allowed. As explained in Sect. 4.4, this mode of reflection by the leaves during the first reflection, which is by far the most energetic one, is more likely to occur than in an isotropic way. This assumption could be easily bypassed by fixing the previous coefficients to 1 .

For the first tree canopy reflection, the part of received direct solar radiation is corrected by the transmitted flux (see Eq. 2):

$T_{0}=\alpha_{\mathrm{t}}\left[\left(S_{\mathrm{t}}^{\Downarrow}-S_{\mathrm{t}}^{\gg}\right)+S_{\mathrm{t}}^{\downarrow}\right]$.

Some uncertainties remain about relevance of sky view or view factors which could formulate to represent reflective contributions from other surfaces at $n$ to the absorption or reflection by the tree layer at $n+1$, as well as potential absorption of energy within the tree's crown. Consequently, the solar flux reflected by "tree" at $n+1$ has been determined as the residual term by assuming that the $n$th solar reflection coming from each element (road, garden, wall A, and wall B) which is not received by road, garden, wall $\mathrm{A}$, wall $\mathrm{B}$, or which is not returned to "sky" at $n+1$ is received by "tree".

During each inter-reflection, a part of $n$th reflected flux which is potentially available for the $(n+1)$ th reflection or absorption is intercepted by high vegetation. This intercepted part related to the presence of foliage on the way of scattered rays towards each receiving element or sky is formulated as the following:

$$
\begin{aligned}
I_{\mathrm{s}}(n+1) & =\Psi_{\mathrm{sr}}\left(1-\tau_{\mathrm{sr}}\right)\left(\delta_{\mathrm{r}} R_{\mathrm{n}}+\delta_{\mathrm{g}} G_{\mathrm{n}}\right) \\
& +\Psi_{\mathrm{sw}}\left(1-\tau_{\mathrm{sw}}\right) \frac{A_{\mathrm{n}}+B_{\mathrm{n}}}{2} \\
I_{\mathrm{r}}(n+1) & =\Psi_{\mathrm{rw}}\left(1-\tau_{\mathrm{rw}}\right) \frac{A_{\mathrm{n}}+B_{\mathrm{n}}}{2} \\
I_{\mathrm{g}}(n+1) & =\Psi_{\mathrm{rw}}\left(1-\tau_{\mathrm{rw}}\right) \frac{A_{\mathrm{n}}+B_{\mathrm{n}}}{2} \\
I_{\mathrm{w}_{\mathrm{A}}}(n+1) & =\Psi_{\mathrm{wr}}\left(1-\tau_{\mathrm{wr}}\right)\left(\delta_{\mathrm{r}} R_{\mathrm{n}}+\delta_{\mathrm{g}} G_{\mathrm{n}}\right) \\
& +\Psi_{\mathrm{ww}}\left(1-\tau_{\mathrm{ww}}\right) B_{\mathrm{n}} \\
I_{\mathrm{w}_{\mathrm{B}}}(n+1) & =\Psi_{\mathrm{wr}}\left(1-\tau_{\mathrm{wr}}\right)\left(\delta_{\mathrm{r}} R_{\mathrm{n}}+\delta_{\mathrm{g}} G_{\mathrm{n}}\right) \\
& +\Psi_{\mathrm{ww}}\left(1-\tau_{\mathrm{ww}}\right) A_{\mathrm{n}} .
\end{aligned}
$$

Finally, the solar flux which is intercepted by "tree" at ( $n+$ 1 ) is expressed as the sum of interceptions on the way of receiving elements of the canyon or sky:

$$
\begin{aligned}
I_{\mathrm{t}}(n+1)= & \frac{1}{\delta_{\mathrm{t}}}\left(I_{\mathrm{s}}(n+1)+\delta_{\mathrm{r}} I_{\mathrm{r}}(n+1) \quad(\mathrm{C} 13)\right. \\
& \left.+\delta_{\mathrm{g}} I_{\mathrm{g}}(n+1)+\frac{2 h}{w} \frac{I_{\mathrm{W}_{\mathrm{A}}}(n+1)+I_{\mathrm{W}_{\mathrm{B}}}(n+1)}{2}\right) .
\end{aligned}
$$

The solar energy which is reflected by tree at $(n+1)$ is consequently

$T_{n+1}=\alpha_{\mathrm{t}} I_{\mathrm{t}}(n+1)$.

The formulations can be simplified by gathering the equations for walls in a single expression for a mean wall according to

$W(n+1)=\frac{A(n+1)+B(n+1)}{2}$.

As a result, after an infinite number of reflections, the equation system can be written as

$$
\begin{aligned}
R_{\infty}= & R_{0}+\alpha_{\mathrm{r}}\left[\Psi_{\mathrm{rw}} \tau_{\mathrm{rw}} W_{\infty}+c_{\mathrm{rt}} \Psi_{\mathrm{rt}} \delta_{\mathrm{t}} T_{\infty}\right] \\
G_{\infty}= & G_{0}+\alpha_{\mathrm{g}}\left[\Psi_{\mathrm{rw}} \tau_{\mathrm{rw}} W_{\infty}+c_{\mathrm{rt}} \Psi_{\mathrm{rt}} \delta_{\mathrm{t}} T_{\infty}\right] \\
W_{\infty}= & W_{0}+\alpha_{\mathrm{w}}\left[\Psi_{\mathrm{ww}} \tau_{\mathrm{ww}} W_{\infty}+\Psi_{\mathrm{wr}} \tau_{\mathrm{rw}}\right. \\
& \left.\left(\delta_{\mathrm{r}} R_{\infty}+\delta_{\mathrm{g}} G_{\infty}\right)+c_{\mathrm{wt}} \Psi_{\mathrm{wt}} \delta_{\mathrm{t}} T_{\infty}\right] \\
T_{\infty}= & T_{0}+\frac{\alpha_{\mathrm{t}}}{\delta_{\mathrm{t}}}\left[\left(\Psi_{\mathrm{sw}}\left(1-\tau_{\mathrm{sw}}\right)+\Psi_{\mathrm{rw}}\left(1-\tau_{\mathrm{rw}}\right)\right.\right. \\
& \left.+\Psi_{\mathrm{ww}}\left(1-\tau_{\mathrm{ww}}\right)\right) W_{\infty}+\left(\Psi_{\mathrm{sr}}\left(1-\tau_{\mathrm{sr}}\right)\right. \\
& \left.\left.+\Psi_{\mathrm{wr}}\left(1-\tau_{\mathrm{wr}}\right)\right)\left(\delta_{\mathrm{r}} R_{\infty}+\delta_{\mathrm{g}} G_{\infty}\right)\right] .
\end{aligned}
$$


As a result, we resolve the linear system of four equations with four unknowns:

$$
\begin{aligned}
R_{\infty}= & R_{0}+\mathcal{F}_{\mathrm{rw}} W_{\infty}+\mathcal{F}_{\mathrm{rt}} T_{\infty} \\
G_{\infty}= & G_{0}+\mathcal{F}_{\mathrm{gw}} W_{\infty}+\mathcal{F}_{\mathrm{gt}} T_{\infty} \\
W_{\infty}= & W_{0}+\mathcal{F}_{\mathrm{ww}} W_{\infty}+\mathcal{F}_{\mathrm{wr}} R_{\infty} \\
& +\mathcal{F}_{\mathrm{wg}} G_{\infty}+\mathcal{F}_{\mathrm{wt}} T_{\infty} \\
T_{\infty}= & T_{0}+\mathcal{F}_{\mathrm{tw}} W_{\infty}+\mathcal{F}_{\mathrm{tr}} R_{\infty}+\mathcal{F}_{\mathrm{tg}} G_{\infty} .
\end{aligned}
$$

The geometric and reflective factors are computed as the following:

$$
\begin{aligned}
\mathcal{F}_{\mathrm{rw}}= & \Psi_{\mathrm{rw}} \tau_{\mathrm{rw}} \alpha_{\mathrm{r}} \\
\mathcal{F}_{\mathrm{rt}}= & c_{\mathrm{rt}} \Psi_{\mathrm{rt}} \delta_{\mathrm{t}} \alpha_{\mathrm{r}} \\
\mathcal{F}_{\mathrm{gw}}= & \Psi_{\mathrm{rw}} \tau_{\mathrm{rw}} \alpha_{\mathrm{g}} \\
\mathcal{F}_{\mathrm{gt}}= & c_{\mathrm{rt}} \Psi_{\mathrm{rt}} \delta_{\mathrm{t}} \alpha_{\mathrm{g}} \\
\mathcal{F}_{\mathrm{wr}}= & \Psi_{\mathrm{wr}} \tau_{\mathrm{wr}} \delta_{\mathrm{r}} \alpha_{\mathrm{w}} \\
\mathcal{F}_{\mathrm{wg}}= & \Psi_{\mathrm{wr}} \tau_{\mathrm{wr}} \delta_{\mathrm{g}} \alpha_{\mathrm{w}} \\
\mathcal{F}_{\mathrm{ww}}= & \Psi_{\mathrm{ww}} \tau_{\mathrm{ww}} \alpha_{\mathrm{w}} \\
\mathcal{F}_{\mathrm{wt}}= & c_{\mathrm{wt}} \Psi_{\mathrm{wt}} \delta_{\mathrm{t}} \alpha_{\mathrm{w}} \\
\mathcal{F}_{\mathrm{tw}}= & {\left[\Psi_{\mathrm{sw}}\left(1-\tau_{\mathrm{sw}}\right)+\Psi_{\mathrm{rw}}\left(1-\tau_{\mathrm{rw}}\right)\right.} \\
& \left.+\Psi_{\mathrm{ww}}\left(1-\tau_{\mathrm{ww}}\right)\right] \frac{1}{\delta_{\mathrm{t}}} \alpha_{t} \\
\mathcal{F}_{\mathrm{tr}}= & {\left[\Psi_{\mathrm{sr}}\left(1-\tau_{\mathrm{sr}}\right)+\Psi_{\mathrm{wr}}\left(1-\tau_{\mathrm{wr}}\right)\right] \frac{\delta_{\mathrm{r}}}{\delta_{\mathrm{t}}} \alpha_{\mathrm{t}} } \\
\mathcal{F}_{\mathrm{tg}}= & {\left[\Psi_{\mathrm{sr}}\left(1-\tau_{\mathrm{sr}}\right)+\Psi_{\mathrm{wr}}\left(1-\tau_{\mathrm{wr}}\right)\right] \frac{\delta_{\mathrm{g}}}{\delta_{\mathrm{t}}} \alpha_{\mathrm{t}} . }
\end{aligned}
$$

The resolution of the equation system gives the following expressions for multiple reflections on tree, walls, road, and garden:

$$
\begin{aligned}
& T_{\infty}=\left(\frac{1-\mathcal{F}_{\mathrm{wr}} \mathcal{F}_{\mathrm{rw}}-\mathcal{F}_{\mathrm{wg}} \mathcal{F}_{\mathrm{gw}}-\mathcal{F}_{\mathrm{ww}}}{\mathcal{D}}\right) T_{0} \\
& +\left(\frac{\mathcal{F}_{\mathrm{tr}}\left(1-\mathcal{F}_{\mathrm{wg}} \mathcal{F}_{\mathrm{gw}}-\mathcal{F}_{\mathrm{ww}}\right)+\mathcal{F}_{\mathrm{wr}}\left(\mathcal{F}_{\mathrm{tg}} \mathcal{F}_{\mathrm{gw}}+\mathcal{F}_{\mathrm{tw}}\right)}{\mathcal{D}}\right) R_{0} \\
& +\left(\frac{\mathcal{F}_{\mathrm{tg}}\left(1-\mathcal{F}_{\mathrm{wr}} \mathcal{F}_{\mathrm{rw}}-\mathcal{F}_{\mathrm{ww}}\right)+\mathcal{F}_{\mathrm{wg}}\left(\mathcal{F}_{\mathrm{tr}} \mathcal{F}_{\mathrm{rw}}+\mathcal{F}_{\mathrm{tw}}\right)}{\mathcal{D}}\right) G_{0} \\
& +\left(\frac{\mathcal{F}_{\mathrm{tr}} \mathcal{F}_{\mathrm{rw}}+\mathcal{F}_{\mathrm{tg}} \mathcal{F}_{\mathrm{gw}}+\mathcal{F}_{\mathrm{tw}}}{\mathcal{D}}\right) W_{0}
\end{aligned}
$$$$
W_{\infty}=\left(\frac{\mathcal{F}_{\mathrm{wr}} \mathcal{F}_{\mathrm{rt}}+\mathcal{F}_{\mathrm{wg}} \mathcal{F}_{\mathrm{gt}}+\mathcal{F}_{\mathrm{wt}}}{\mathcal{D}}\right) T_{0}
$$

$$
\begin{aligned}
& +\left(\frac{\mathcal{F}_{\mathrm{wr}}\left(1-\mathcal{F}_{\mathrm{tg}} \mathcal{F}_{\mathrm{gt}}\right)+\mathcal{F}_{\mathrm{tr}}\left(\mathcal{F}_{\mathrm{wg}} \mathcal{F}_{\mathrm{gt}}+\mathcal{F}_{\mathrm{wt}}\right)}{\mathcal{D}}\right) R_{0} \\
& +\left(\frac{\mathcal{F}_{\mathrm{wg}}\left(1-\mathcal{F}_{\mathrm{tr}} \mathcal{F}_{\mathrm{rt}}\right)+\mathcal{F}_{\mathrm{tg}}\left(\mathcal{F}_{\mathrm{wr}} \mathcal{F}_{\mathrm{rt}}+\mathcal{F}_{\mathrm{wt}}\right)}{\mathcal{D}}\right) G_{0} \\
& +\left(\frac{1-\mathcal{F}_{\mathrm{rt}} \mathcal{F}_{\mathrm{tr}}-\mathcal{F}_{\mathrm{tg}} \mathcal{F}_{\mathrm{gt}}}{\mathcal{D}}\right) W_{0}
\end{aligned}
$$

$$
\begin{aligned}
R_{\infty}= & \left(\frac{\mathcal{F}_{\mathrm{rw}}\left(\mathcal{F}_{\mathrm{rt}} \mathcal{F}_{\mathrm{wr}}+\mathcal{F}_{\mathrm{gt}} \mathcal{F}_{\mathrm{wg}}+\mathcal{F}_{\mathrm{wt}}\right)+\mathcal{F}_{\mathrm{rt}}\left(1-\mathcal{F}_{\mathrm{wr}} \mathcal{F}_{\mathrm{rw}}-\mathcal{F}_{\mathrm{wg}} \mathcal{F}_{\mathrm{gw}}-\mathcal{F}_{\mathrm{ww}}\right)}{\mathcal{D}}\right) T_{0} \\
& +\left(1+\frac{\mathcal{F}_{\mathrm{rw}}\left(\mathcal{F}_{\mathrm{wr}}\left(1-\mathcal{F}_{\mathrm{tg}} \mathcal{F}_{\mathrm{gt}}\right)+\mathcal{F}_{\mathrm{tr}}\left(\mathcal{F}_{\mathrm{wg}} \mathcal{F}_{\mathrm{gt}}+\mathcal{F}_{\mathrm{wt}}\right)\right)+\mathcal{F}_{\mathrm{rt}}\left(\mathcal{F}_{\mathrm{tr}}\left(1-\mathcal{F}_{\mathrm{wg}} \mathcal{F}_{\mathrm{gw}}\right)+\mathcal{F}_{\mathrm{wr}}\left(\mathcal{F}_{\mathrm{tg}} \mathcal{F}_{\mathrm{gw}}+\mathcal{F}_{\mathrm{tw}}\right)\right)}{\mathcal{D}}\right) R_{0} \\
& +\left(\frac{\mathcal{F}_{\mathrm{rw}}\left(\mathcal{F}_{\mathrm{wg}}\left(1-\mathcal{F}_{\mathrm{tr}} \mathcal{F}_{\mathrm{rt}}\right)+\mathcal{F}_{\mathrm{tg}}\left(\mathcal{F}_{\mathrm{wr}} \mathcal{F}_{\mathrm{rt}}+\mathcal{F}_{\mathrm{wt}}\right)\right)+\mathcal{F}_{\mathrm{rt}}\left(\mathcal{F}_{\mathrm{tg}}\left(1-\mathcal{F}_{\mathrm{wr}} \mathcal{F}_{\mathrm{rw}}-\mathcal{F}_{\mathrm{ww}}\right)+\mathcal{F}_{\mathrm{wg}}\left(\mathcal{F}_{\mathrm{tr}} \mathcal{F}_{\mathrm{rw}}+\mathcal{F}_{\mathrm{tw}}\right)\right)}{\mathcal{D}}\right) G_{0} \\
& +\left(\frac{\mathcal{F}_{\mathrm{rt}}\left(\mathcal{F}_{\mathrm{tr}} \mathcal{F}_{\mathrm{rw}}+\mathcal{F}_{\mathrm{tg}} \mathcal{F}_{\mathrm{gw}}+\mathcal{F}_{\mathrm{tw}}\right)+\mathcal{F}_{\mathrm{rw}}\left(1-\mathcal{F}_{\mathrm{tr}} \mathcal{F}_{\mathrm{rt}}-\mathcal{F}_{\mathrm{tg}} \mathcal{F}_{\mathrm{gt}}\right)}{\mathcal{D}}\right) W_{0}
\end{aligned}
$$




$$
\begin{aligned}
G_{\infty}= & \left(\frac{\mathcal{F}_{\mathrm{gw}}\left(\mathcal{F}_{\mathrm{rt}} \mathcal{F}_{\mathrm{wr}}+\mathcal{F}_{\mathrm{gt}} \mathcal{F}_{\mathrm{wg}}+\mathcal{F}_{\mathrm{wt}}\right)+\mathcal{F}_{\mathrm{gt}}\left(1-\mathcal{F}_{\mathrm{wr}} \mathcal{F}_{\mathrm{rw}}-\mathcal{F}_{\mathrm{wg}} \mathcal{F}_{\mathrm{gw}}-\mathcal{F}_{\mathrm{ww}}\right)}{\mathcal{D}}\right) T_{0} \\
& +\left(\frac{\mathcal{F}_{\mathrm{gw}}\left(\mathcal{F}_{\mathrm{wr}}\left(1-\mathcal{F}_{\mathrm{tg}} \mathcal{F}_{\mathrm{gt}}\right)+\mathcal{F}_{\mathrm{tr}}\left(\mathcal{F}_{\mathrm{wg}} \mathcal{F}_{\mathrm{gt}}+\mathcal{F}_{\mathrm{wt}}\right)\right)+\mathcal{F}_{\mathrm{gt}}\left(\mathcal{F}_{\mathrm{tr}}\left(1-\mathcal{F}_{\mathrm{wg}} \mathcal{F}_{\mathrm{gw}}\right)+\mathcal{F}_{\mathrm{wr}}\left(\mathcal{F}_{\mathrm{tg}} \mathcal{F}_{\mathrm{gw}}+\mathcal{F}_{\mathrm{tw}}\right)\right)}{\mathcal{D}}\right) R_{0} \\
& +\left(1+\frac{\mathcal{F}_{\mathrm{gw}}\left(\mathcal{F}_{\mathrm{wg}}\left(1-\mathcal{F}_{\mathrm{tr}} \mathcal{F}_{\mathrm{rt}}\right)+\mathcal{F}_{\mathrm{tg}}\left(\mathcal{F}_{\mathrm{wr}} \mathcal{F}_{\mathrm{rt}}+\mathcal{F}_{\mathrm{wt}}\right)\right)+\mathcal{F}_{\mathrm{gt}}\left(\mathcal{F}_{\mathrm{tg}}\left(1-\mathcal{F}_{\mathrm{wr}} \mathcal{F}_{\mathrm{rw}}-\mathcal{F}_{\mathrm{ww}}\right)+\mathcal{F}_{\mathrm{wg}}\left(\mathcal{F}_{\mathrm{tr}} \mathcal{F}_{\mathrm{rw}}+\mathcal{F}_{\mathrm{tw}}\right)\right)}{\mathcal{D}}\right) G_{0} \\
& +\left(\frac{\mathcal{F}_{\mathrm{gt}}\left(\mathcal{F}_{\mathrm{tr}} \mathcal{F}_{\mathrm{rw}}+\mathcal{F}_{\mathrm{tg}} \mathcal{F}_{\mathrm{gw}}+\mathcal{F}_{\mathrm{tw}}\right)+\mathcal{F}_{\mathrm{gw}}\left(1-\mathcal{F}_{\mathrm{tr}} \mathcal{F}_{\mathrm{rt}}-\mathcal{F}_{\mathrm{tg}} \mathcal{F}_{\mathrm{gt}}\right)}{\mathcal{D}}\right) W_{0}
\end{aligned}
$$

The denominator is expressed as the following:

$\mathcal{D}=\left(1-\mathcal{F}_{\mathrm{wr}} \mathcal{F}_{\text {rw }}-\mathcal{F}_{\mathrm{wg}} \mathcal{F}_{\mathrm{gw}}-\mathcal{F}_{\mathrm{ww}}\right)\left(1-\mathcal{F}_{\text {tr }} \mathcal{F}_{\text {rt }}-\mathcal{F}_{\text {tg }} \mathcal{F}_{\mathrm{gt}}\right)-\left(\mathcal{F}_{\mathrm{wr}} \mathcal{F}_{\text {rt }}+\mathcal{F}_{\mathrm{wg}} \mathcal{F}_{\mathrm{gt}}+\mathcal{F}_{\mathrm{wt}}\right)\left(\mathcal{F}_{\text {tr }} \mathcal{F}_{\text {rw }}+\mathcal{F}_{\text {tg }} \mathcal{F}_{\text {gw }}+\mathcal{F}_{\text {tw }}\right)$. 
Competing interests. The authors declare that they have no conflict of interest.

Acknowledgements. We acknowledge Laurent Malys for his technical support on the first SOLENE runs. We thank the anonymous reviewers for their helpful comments.

Edited by: T. Poulet

Reviewed by: two anonymous referees

\section{References}

Abdel-Aziz, D. M., Shboul, A. A., and Al-Kurdi, N. Y.: Effects of Tree Shading on Building's Energy Consumption - The Case of Residential Buildings in a Mediterranean Climate, Am. J. Environ. Eng., 5, 131-140, doi:10.5923/j.ajee.20150505.01, 2015.

Akbari, H., Kurn, D. M., Bretz, S. E., and Hanford, J. W.: Peak power and cooling energy savings of shade trees, Energ. Buildings, 25, 139-148, 1997.

Akbari, H., Pomerantz, M., and Taha, H.: Cool surfaces and shade trees to reduce energy use and improve air quality in urban areas, Sol. Energy, 70, 295-310, doi:10.1016/S0038-092X(00)00089X, 2001.

Alavipanah, S., Wegmann, M., Qureshi, S., Weng, Q., and Koellner, T.: The Role of Vegetation in Mitigating Urban Land Surface Temperatures: A Case Study of Munich, Germany during the Warm Season, Sustainability, 7, 4689-4706, doi:10.3390/su7044689, 2015.

Alvey, A. A.: Promoting and preserving biodiversity in the urban forest, Urban For. Urban Gree., 5, 195-201, doi:10.1016/j.ufug.2006.09.003, 2006.

Armson, D., Stringer, P., and Ennos, A. R.: The effect of street trees and amenity grass on urban surface water runoff in Manchester, UK, Urban For. Urban Gree., 12, 282-286, doi:10.1016/j.ufug.2013.04.001, 2013.

Barcelona City Council: Street Tree Management in Barcelona, Tech. rep., 2011.

Bertram, C. and Rehdanz, K.: The role of urban green space for human well-being, Ecol. Econ., 120, 139-152, 2015.

Boone, A., Calvet, J.-C., and Noilhan, J.: Inclusion of a Third Soil Layer in a Land Surface Scheme Using the Force-Restore Method, J. Appl. Meteorol., 38, 1611-1630, doi:10.1175/15200450(1999)038<1611:IOATSL>2.0.CO;2, 1999.

Bouyer, J., Inard, C., and Musy, M.: Microclimatic coupling as a solution to improve building energy simulation in an urban context, Energ. Buildings, 43, 1549-1559, doi:10.1016/j.enbuild.2011.02.010, 2011.

Bowen, K. J. and Parry, M.: The evidence base for linkages between green infrastructure, public health and economic benefit, Tech. rep., 2015.

Bruse, M. and Fleer, H.: Simulating surface-plant-air interactions inside urban environments with a three dimensional numerical model, Environ. Modell. Softw., 13, 373-384, doi:10.1016/S1364-8152(98)00042-5, 1998.

Campbell, G. S. and Norman, J. M.: The description and measurement of plant canopy structure, Cambridge University Press, UK, 1989.
City of Westminster: Trees and the Public Realm ( Draft ), Tech. Rep. December, 2009.

Coutts, A. M., White, E. C., Tapper, N. J., Beringer, J., and Livesley, S. J.: Temperature and human thermal comfort effects of street trees across three contrasting street canyon environments, Theor. Appl. Climatol., 124, 55-68, doi:10.1007/s00704-015-1409-y, 2015.

de Abreu-Harbich, L. V., Labaki, L. C., and Matzarakis, A.: Effect of tree planting design and tree species on human thermal comfort in the tropics, Landscape Urban Plan., 138, 99-109, doi:10.1016/j.landurbplan.2015.02.008, 2015.

De Brichambaut, C. P.: Rayonnement solaire et échanges radiatifs naturels: méthodes actinométriques, Gauthier-Villars, 1963.

de Munck, C.: Modélisation de la végétation urbaine et stratégies d'adaptation pour l'amélioration du confort climatique et de la demande énergétique en ville, $\mathrm{PhD}$ thesis, Université Toulouse III, available at: http://oatao.univ-toulouse.fr/9278/, 2013.

Feyisa, G. L., Dons, K., and Meilby, H.: Efficiency of parks in mitigating urban heat island effect: An example from Addis Ababa, Landscape Urban Plan., 123, 87-95, doi:10.1016/j.landurbplan.2013.12.008, 2014.

Grimmond, C. S. B., Blackett, M., Best, M. J., Baik, J.-J., Belcher, S. E., Beringer, J., Bohnenstengel, S. I., Calmet, I., Chen, F., Coutts, A., Dandou, A., Fortuniak, K., Gouvea, M. L., Hamdi, R., Hendry, M., Kanda, M., Kawai, T., Kawamoto, Y., Kondo, H., Krayenhoff, E. S., Lee, S.-H., Loridan, T., Martilli, A., Masson, V., Miao, S., Oleson, K., Ooka, R., Pigeon, G., Porson, A., Ryu, Y.-H., Salamanca, F., Steeneveld, G., Tombrou, M., Voogt, J. A., Young, D. T., and Zhang, N.: Initial results from Phase 2 of the international urban energy balance model comparison, Int. J. Climatol., 31, 244-272, doi:10.1002/joc.2227, 2011.

Groleau, D. and Mestayer, P. G.: Urban Morphology Influence on Urban Albedo: A Revisit with the SOLENE Model, Bound.Lay. Meteorol., 147, 301-327, doi:10.1007/s10546-012-9786-6, 2013.

Hamdi, R. and Masson, V.: Inclusion of a Drag Approach in the Town Energy Balance (TEB) Scheme: Offline 1D Evaluation in a Street Canyon, J. Appl. Meteorol. Clim., 47, 2627-2644, doi:10.1175/2008JAMC1865.1, 2008.

Harman, I. N. and Belcher, S. E.: The surface energy balance and boundary layer over urban street canyons, Q. J. Roy. Meteor. Soc., 132, 2749-2768, doi:10.1256/qj.05.185, 2006.

Hien, W. N., Puay Yok, T. P., and Yu, C.: Study of thermal performance of extensive rooftop greenery systems in the tropical climate, Build. Environ., 42, 25-54, doi:10.1016/j.buildenv.2005.07.030, 2007.

Hottel, H. C.: Radiant-Heat Transmission, in: Heat Transmission, edited by: Mc Adams, W. H., Mc Graw-Hill, 55-125, 1954.

Jim, C. Y.: Air-conditioning energy consumption due to green roofs with different building thermal insulation, Appl. Energ., 128, 4959, doi:10.1016/j.apenergy.2014.04.055, 2014.

Joshi, N. and Joshi, A.: Role of Urban Trees in Amelioration of Temperatures, Int. J. Res. Stud. Biosci., 3, 132-137, 2015.

Ko, Y., Lee, J.-H., McPherson, E. G., and Roman, L. A.: Long-term monitoring of Sacramento Shade program trees: Tree survival, growth and energy-saving performance, Landscape Urban Plan., 143, 183-191, doi:10.1016/j.landurbplan.2015.07.017, 2015.

Kokogiannakis, G., Tietje, A., and Darkwa, J.: The role of Green Roofs on Reducing Heating and Cooling Loads: A Database 
across Chinese Climates, Procedia Environ. Sci., 11, 604-610, doi:10.1016/j.proenv.2011.12.094, 2011.

Kounkou-Arnaud, R., Desplat, J., Lemonsu, A., and Salagnac, J.-L.: Epicea : étude des impacts du changement climatique à Paris, La Météorologie, 8, 42-48, doi:10.4267/2042/53186, 2014.

Krayenhoff, E. S., Christen, A., Martilli, A., and Oke, T. R.: A Multi-layer Radiation Model for Urban Neighbourhoods with Trees, Bound.-Lay. Meteorol., 151, 139-178, doi:10.1007/s10546-013-9883-1, 2014.

Krayenhoff, E. S., Santiago, J. L., Martilli, A., Christen, A., and Oke, T. R.: Parametrization of Drag and Turbulence for Urban Neighbourhoods with Trees, Bound.-Lay. Meteorol., 156, 157189, doi:10.1007/s10546-015-0028-6, 2015.

Lafore, J. P., Stein, J., Asencio, N., Bougeault, P., Ducrocq, V., Duron, J., Fischer, C., Héreil, P., Mascart, P., Masson, V., Pinty, J. P., Redelsperger, J. L., Richard, E., and Vilà-Guerau De Arellano, J.: The Meso-NH Atmospheric Simulation System, Part I: Adiabatic formulation and control simulations, Ann. Geophys., 16, 90-109, doi:10.1007/s005850050582, 1997.

Lee, S.-H. and Park, S.-U.: A Vegetated Urban Canopy Model for Meteorological and Environmental Modelling, Bound.-Lay. Meteorol., 126, 73-102, doi:10.1007/s10546-007-9221-6, 2008.

Lemonsu, A., Grimmond, C. S. B., and Masson, V.: Modeling the Surface Energy Balance of the Core of an Old Mediterranean City: Marseille, J. Appl. Meteorol., 43, 312-327, 2004.

Lemonsu, A., Bélair, S., Mailhot, J., and Leroyer, S.: Evaluation of the Town Energy Balance model in cold and snowy conditions during the Montreal Urban Snow Experiment 2005, J. Appl. Meteorol. Clim., 49, 346-362, doi:10.1175/2009JAMC2131.1, 2010.

Lemonsu, A., Masson, V., Shashua-Bar, L., Erell, E., and Pearlmutter, D.: Inclusion of vegetation in the Town Energy Balance model for modelling urban green areas, Geosci. Model Dev., 5, 1377-1393, doi:10.5194/gmd-5-1377-2012, 2012.

Lemonsu, A., Kounkou-Arnaud, R., Desplat, J., Salagnac, J.-L., and Masson, V.: Evolution of the Parisian urban climate under a global changing climate, Clim. Change, 116, 679-692, doi:10.1007/s10584-012-0521-6, 2013.

Malys, L.: Modélisation de la végétation urbaine et stratégies d'adaptation pour l'amélioration du confort climatique et de la demande énergétique en ville, PhD thesis, Ecole Centrale de Nantes, France, 2012.

Malys, L., Musy, M., and Inard, C.: A hydrothermal model to assess the impact of green walls on urban microclimate and building energy consumption, Build. Environ., 73, 187-197, doi:10.1016/j.buildenv.2013.12.012, 2014.

Masson, V.: A physically-based scheme for the urban energy budget in atmospheric models, Bound.-Lay. Meteorol., 94, 357-397, 2000.

Masson, V. and Seity, Y.: Including Atmospheric Layers in Vegetation and Urban Offline Surface Schemes, J. Appl. Meteorol. Clim., 48, 1377-1397, doi:10.1175/2009JAMC1866.1, 2009.

Masson, V., Grimmond, C. S. B., and Oke, T. R.: Evaluation of the Town Energy Balance (TEB) Scheme with Direct Measurements from Dry Districts in Two Cities, J. Appl. Meteorol., 41, 10111026, 2002.

Masson, V., Le Moigne, P., Martin, E., Faroux, S., Alias, A., Alkama, R., Belamari, S., Barbu, A., Boone, A., Bouyssel, F., Brousseau, P., Brun, E., Calvet, J.-C., Carrer, D., Decharme, B.,
Delire, C., Donier, S., Essaouini, K., Gibelin, A.-L., Giordani, H., Habets, F., Jidane, M., Kerdraon, G., Kourzeneva, E., Lafaysse, M., Lafont, S., Lebeaupin Brossier, C., Lemonsu, A., Mahfouf, J.-F., Marguinaud, P., Mokhtari, M., Morin, S., Pigeon, G., Salgado, R., Seity, Y., Taillefer, F., Tanguy, G., Tulet, P., Vincendon, B., Vionnet, V., and Voldoire, A.: The SURFEXv7.2 land and ocean surface platform for coupled or offline simulation of earth surface variables and fluxes, Geosci. Model Dev., 6, 929-960, doi:10.5194/gmd-6-929-2013, 2013.

Miguet, F.: Paramètres physiques des ambiances architecturales : Un modèle numérique pour la simulation de la lumière naturelle dans le projet urbain, $\mathrm{PhD}$ thesis, available at: https: //tel.archives-ouvertes.fr/tel-00546996/, 2000.

Miguet, F. and Groleau, D.: A daylight simulation tool for urban and architectural spaces-application to transmitted direct and diffuse light through glazing, Build. Environ., 37, 833-843, doi:10.1016/S0360-1323(02)00049-5, 2002.

Mullaney, J., Lucke, T., and Trueman, S. J.: A review of benefits and challenges in growing street trees in paved urban environments, Landscape Urban Plan., 134, 157-166, doi:10.1016/j.landurbplan.2014.10.013, 2015.

Municipality of Toulouse: CAHIER DE L'ESPACE PUBLIC "LES ESPACES VERTS”, Tech. rep., Toulouse, France, 2008.

Noilhan, J. and Planton, S.: A Simple Parameterization of Land Surface Processes for Meteorological Models, Mon. Weather Rev., 117, 536-549, 1989.

Nowak, D. J. and Dwyer, J. F.: Understanding the Benefits and Costs of Urban Forest Ecosystems, in: Handbook of Urban and Community Forestry in the North East, 25-46, doi:10.1007/9781-4020-4289-8_2, 2007.

Önder, S. and Akay, A.: The Roles of Plants on Mitigating the Urban Heat Islands' Negative Effects, Int. J. Agric Econom. Dev., 2, 18-32, 2014.

Park, M., Hagishima, A., Tanimoto, J., and Narita, K. I.: Effect of urban vegetation on outdoor thermal environment: Field measurement at a scale model site, Build. Environ., 56, 38-46, doi:10.1016/j.buildenv.2012.02.015, 2012.

Perez, R., Seals, R., and Michalsky, J.: All-weather model for sky luminance distribution-Preliminary configuration and validation, Sol. Energy, 50, 235-245, doi:10.1016/0038-092X(93)90017-I, 1993.

Pigeon, G., Moscicki, M. A., Voogt, J. A., and Masson, V.: Simulation of fall and winter surface energy balance over a dense urban area using the TEB scheme, Meteorol. Atmos. Phys., 102, 159-171, 2008.

Porson, A., Harman, I. N., Bohnenstengel, S. I., and Belcher, S. E.: How many facets are needed to represent the surface energy balance of an urban area?, Bound.-Lay. Meteorol., 132, 107-128, doi:10.1007/s10546-009-9392-4, 2009.

Qiu, G. Y., Li, H. Y., Zhang, Q. T., Chen, W., Liang, X. J., and Li, X. Z.: Effects of Evapotranspiration on Mitigation of Urban Temperature by Vegetation and Urban Agriculture, J. Integr. Agricult., 12, 1307-1315, doi:10.1016/S2095-3119(13)60543-2, 2013.

Robitu, M., Musy, M., Inard, C., and Groleau, D.: Modeling the influence of vegetation and water pond on urban microclimate, Sol. Energy, 80, 435-447, doi:10.1016/j.solener.2005.06.015, 2006.

Ryu, Y. H., Bou-Zeid, E., Wang, Z. H., and Smith, J. A.: Realistic Representation of Trees in an Urban Canopy Model, Bound.- 
Lay. Meteorol., 159, 193-220, doi:10.1007/s10546-015-0120-y, 2015.

Seity, Y., Brousseau, P., Malardel, S., Hello, G., Bénard, P., Bouttier, F., Lac, C., and Masson, V.: The AROME-France ConvectiveScale Operational Model, Mon. Weather Rev., 139, 976-991, doi:10.1175/2010MWR3425.1, 2011.

Shashua-Bar, L., Pearlmutter, D., and Erell, E.: The influence of trees and grass on outdoor thermal comfort in a hot-arid environment, Int. J. Climatol., 31, 1498-1506, doi:10.1002/joc.2177, 2011.

Simpson, J. R.: Improved estimates of tree-shade effects on residential energy use, Energ. Buildings, 34, 1067-1076, doi:10.1016/S0378-7788(02)00028-2, 2002.

Spangenberg, J., Shinzato, P., Johansson, E., and Duarte, D. H. S.: Simulation of the influence of vegetation on microclimate and thermal comfort in the city of São Paulo, Rev. Soc. Bras. Arborização Urbana, 3, 1-19, doi:10.1016/j.solener.2005.06.015, 2008.

Taleghani, M., Sailor, D., and Ban-Weiss, G. A.: Micrometeorological simulations to predict the impacts of heat mitigation strategies on pedestrian thermal comfort in a Los Angeles neighborhood, Environ. Res. Lett., 11, 024003, doi:10.1088/17489326/11/2/024003, 2016.

Tavares, R., Calmet, I., and Dupont, S.: Modelling the impact of green infrastructures on local microclimate within an idealized homogeneous urban canopy, 9th International Conference on Urban Climate (ICUC9), Toulouse (France), 20-24 July 2015, 1-6, 2015.
Wang, Z.-H.: Monte Carlo simulations of radiative heat exchange in a street canyon with trees, Sol. Energy, 110, 704-713, doi:10.1016/j.solener.2014.10.012, 2014.

Yamada, T.: A numerical study of turbulent airflow in and above a forest canopy, J. Meteorol. Soc. Jpn., 60, 439-454, 1982.

Yao, L., Chen, L., Wei, W., and Sun, R.: Potential reduction in urban runoff by green spaces in Beijing: A scenario analysis, Urban For. Urban Gree., 14, 300-308, doi:10.1016/j.ufug.2015.02.014, 2015.

Young, D. T., Clark, P., Hendry, M., and Barlow, J.: Modelling Radiative Exchange in a Vegetated Urban Street Canyon Model, 9th International Conference on Urban Climate (ICUC9), Toulouse (France), 20-24 July 2015, 1-5, 2015.

Zhang, B., Xie, G.-d., Li, N., and Wang, S.: Effect of urban green space changes on the role of rainwater runoff reduction in Beijing, China, Landscape Urban Plan., 140, 8-16, doi:10.1016/j.landurbplan.2015.03.014, 2015.

Zhang, Z., Lv, Y., and Pan, H.: Cooling and humidifying effect of plant communities in subtropical urban parks, Urban For. Urban Gree., 12, 323-329, doi:10.1016/j.ufug.2013.03.010, 2013. 